Portland State University

PDXScholar

$10-2021$

\title{
New Mobility For All: Evaluation of a Transportation Incentive Program for Residents of Affordable Housing in Portland, OR
}

\author{
Nathan McNeil \\ Portland State University, nmcneil@pdx.edu \\ John MacArthur \\ Portland State University, macarthur@pdx.edu \\ Huijun Tan \\ Portland State University
}

Follow this and additional works at: https://pdxscholar.library.pdx.edu/trec_reports

Part of the Transportation Commons, Urban Studies Commons, and the Urban Studies and Planning Commons

Let us know how access to this document benefits you.

\section{Recommended Citation}

McNeil, Nathan, John MacArthur, and Huijun Tan. New Mobility For All: Evaluation of a Transportation Incentive Program for Residents of Affordable Housing in Portland, Oregon. NITC-RR-1318. Portland, OR: Transportation Research and Education Center (TREC), 2021. https://dx.doi.org/10.15760/trec.265

This Report is brought to you for free and open access. It has been accepted for inclusion in TREC Final Reports by an authorized administrator of PDXScholar. Please contact us if we can make this document more accessible: pdxscholar@pdx.edu. 


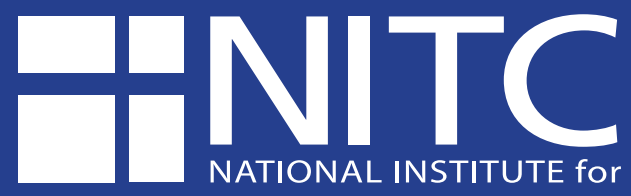

Final Report 1318 October 2021 TRANSPORTATION and COMMUNITIES
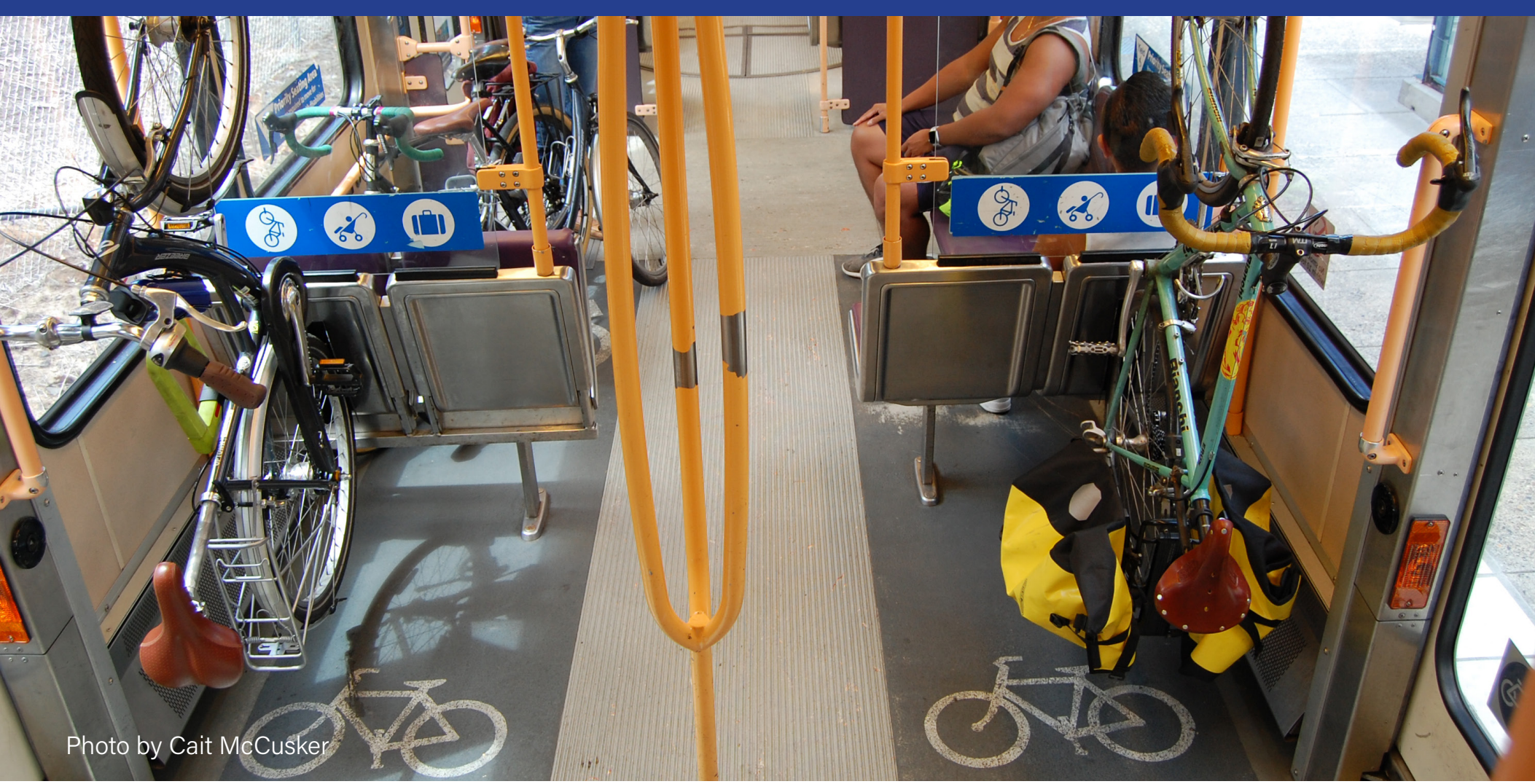

\title{
New Mobility For All: Evaluation of a Transportation Incentive Program for Residents of Affordable Housing in Portland, OR
}

\author{
Nathan McNeil \\ John MacArthur \\ Huijun Tan
}

\section{\& Portland State}




\title{
New Mobility For All: \\ Evaluation of a Transportation Incentive Program for Residents of Affordable Housing in Portland, OR
}

Final Report

NITC-RR-1318

\author{
by \\ Nathan McNeil \\ John MacArthur \\ Huijun Tan \\ Portland State University
}

for

National Institute for Transportation and Communities (NITC)

P.O. Box 751

Portland, OR 97207
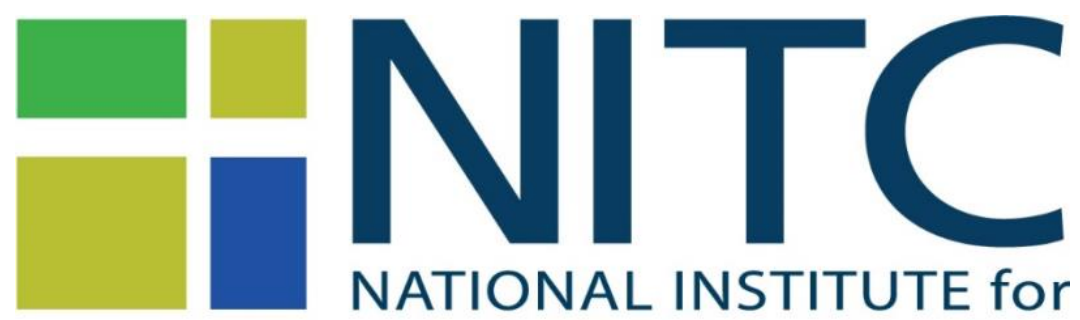

TRANSPORTATION and COMMUNITIES

October 2021 


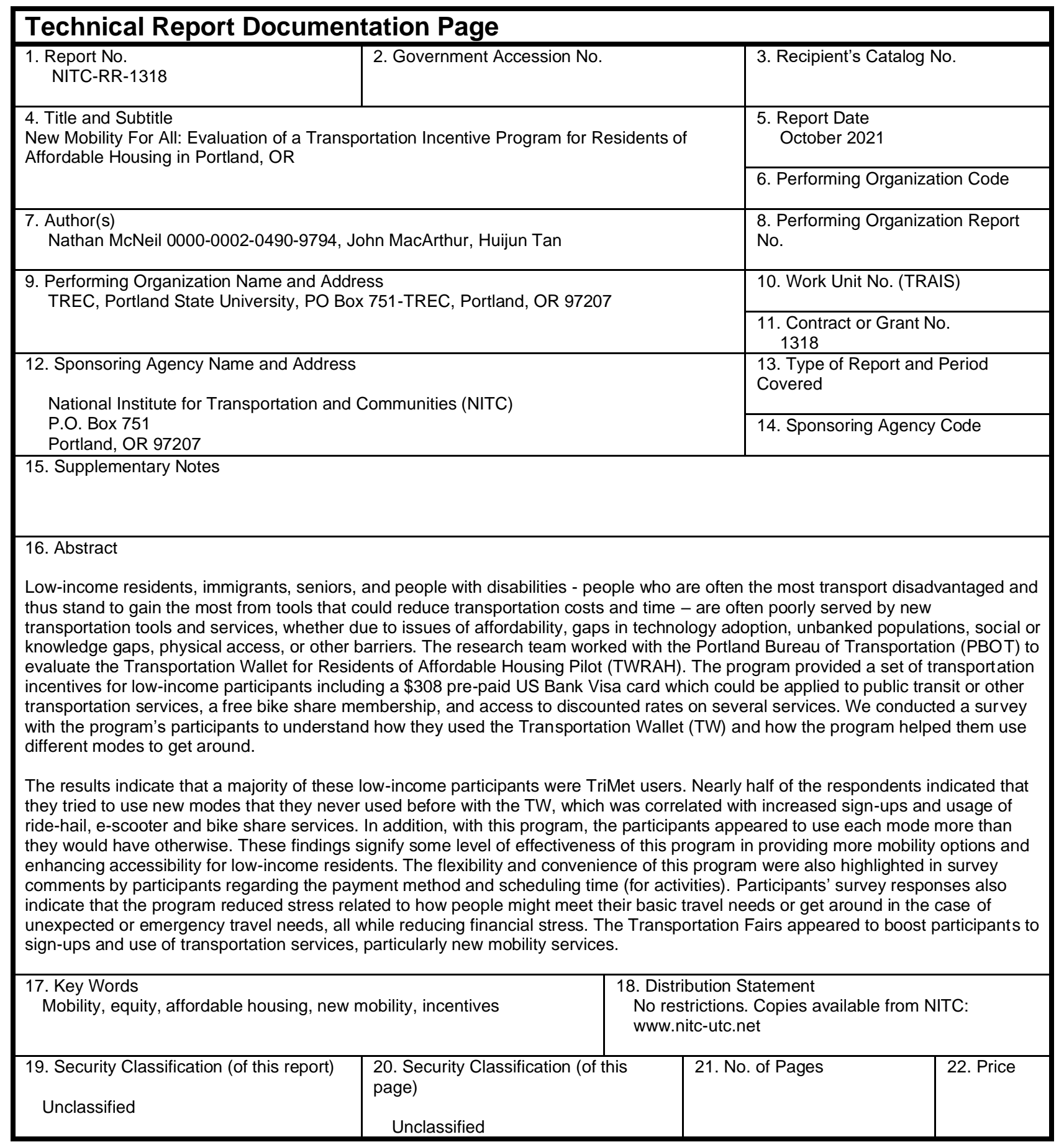




\section{ACKNOWLEDGEMENTS}

This project was funded by the National Institute for Transportation and Communities (NITC; grant number 1318), a U.S. DOT University Transportation Center.

\section{DISCLAIMER}

The contents of this report reflect the views of the authors, who are solely responsible for the facts and the accuracy of the material and information presented herein. This document is disseminated under the sponsorship of the U.S. Department of Transportation University Transportation Centers Program in the interest of information exchange. The U.S. Government assumes no liability for the contents or use thereof. The contents do not necessarily reflect the official views of the U.S. Government. This report does not constitute a standard, specification, or regulation.

\section{RECOMMENDED CITATION}

McNeil, Nathan, John MacArthur, and Huijun Tan. New Mobility For All: Evaluation of a Transportation Incentive Program for Residents of Affordable Housing in Portland, Oregon. NITC-RR-1318. Portland, OR: Transportation Research and Education Center (TREC), 2021. 


\section{CONTENTS}

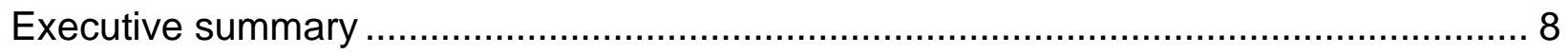

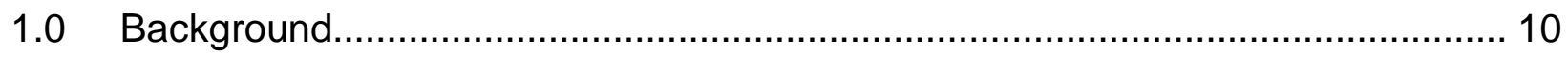

1.1 Transportation Wallet for Residents of Affordable Housing ........................... 10

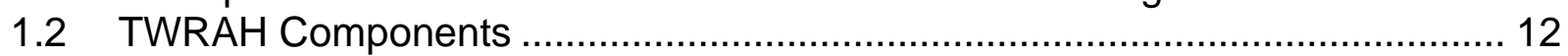

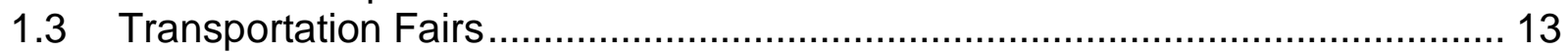

1.4 Data collection and research objectives.................................................... 13

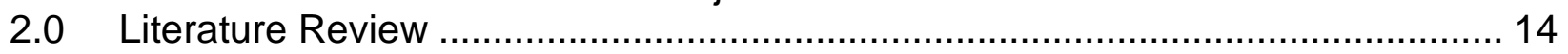

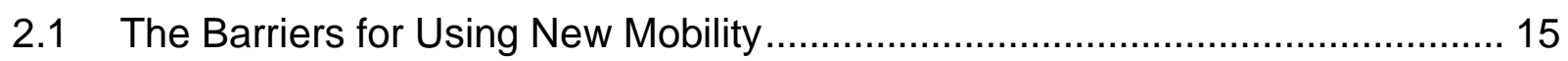

2.2 Transportation Programs for Low-income Groups...................................... 16

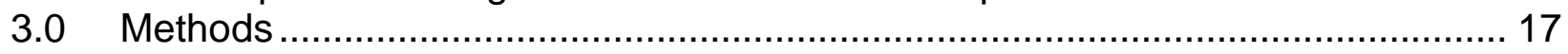

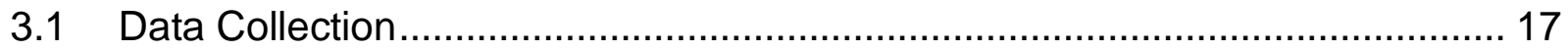

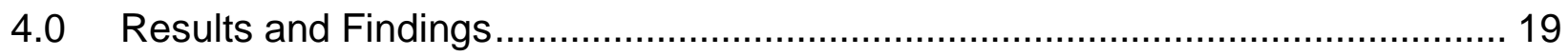

4.1 Background and Demographics of Participants........................................... 19

4.2 The Transportation Wallet and Services/Modes Used ................................... 20

4.2.1 TriMet Transit Sign-ups and Usage ................................................... 21

4.2.2 Sign-up and Usage of Other Transportation Services .............................. 24

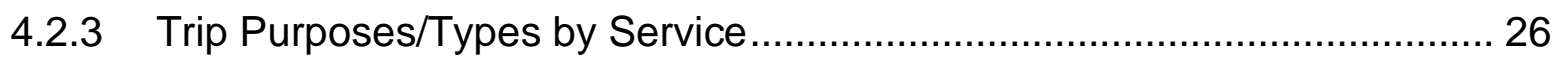

4.3 The effect of mode choice and activity access with the Transportation Wallet. 28

4.3.1 Did the Program Increase Usage of New Mobility Services? ..................... 29

4.3.2 Did the Program Increase Access for Participants? ................................ 30

4.3.3 Will People Continue to Use the Services? .............................................. 31

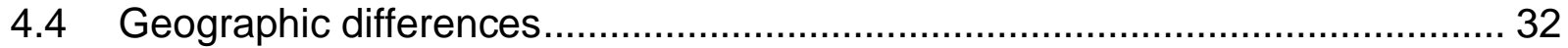

4.5 Transportation Fair and program implementation .......................................... 33

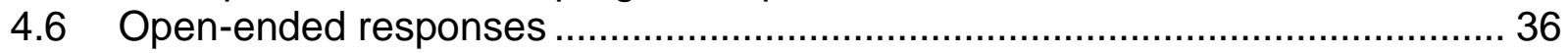

4.6.1 Best Things About the Transportation Wallet.......................................... 36

4.6.2 What Participants Would Change with the TW Program ............................. 39

4.7 Transportation Wallet Card Balances.......................................................... 41

5.0 Findings from provider interviews and debrief............................................... 44

5.1 Value of having fairs located at residence locations ...................................... 44

5.2 Freedom to choose how to spend transportation funds ................................ 44

5.3 Challenge of providing interpretation and translation services........................ 44

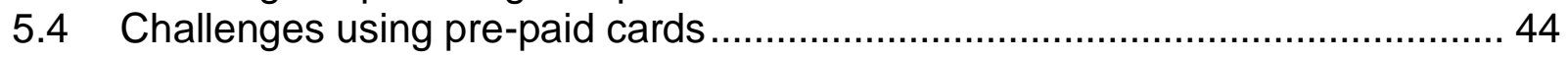

5.5 Program as discount program enrollment mechanism .................................. 45

5.6 Acknowledgement of resident coordinator role ............................................ 45

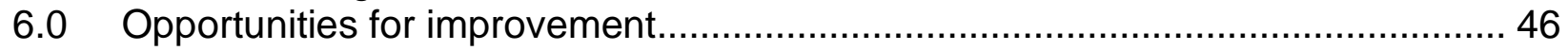

6.1 TWRAH participants would benefit for more ongoing assistance .................... 46

6.2 More opportunities to meet services providers ............................................. 46 
6.3 Activated cards at fairs ........................................................................... 46

6.4 Explore ways to help participants better understand TriMet fare-capping ........ 46

6.5 Explore ways to ensure participants spend down their pre-paid cards............. 47

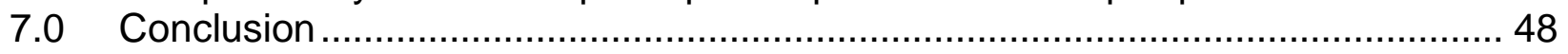

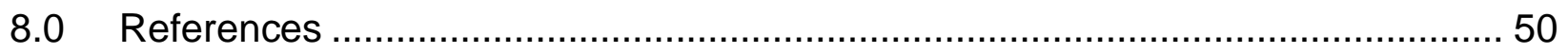

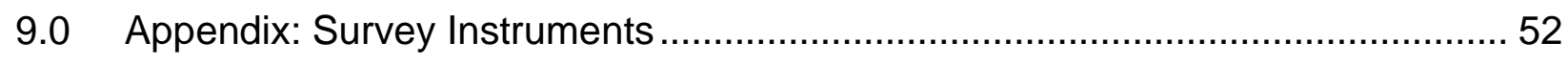




\section{Tables}

Table 1: Affordable housing organizations participating in the TWRAH pilot program .. 11

Table 2: Social-demographics of the participants .................................................... 19

Table 3: Participant mobility and access questions ............................................... 20

Table 4: Enrollment in TriMet reduced fare program ............................................ 24

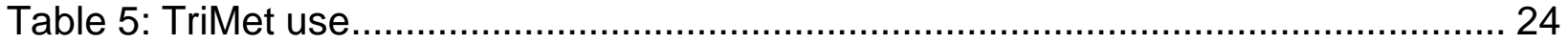

Table 6: Percentage of respondents signing up for ride-hail, BIKETOWN, and e-

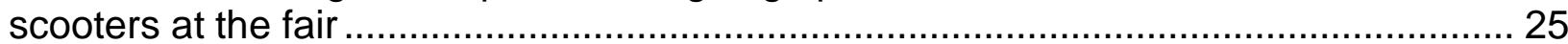

Table 7: Percentage of respondents who used each type of service ........................... 25

Table 8: Percentage of respondents reporting each trip purpose, by each type of service

Table 9: TWRAH stated impact on travel behavior, by geographic area ……….......... 32

Table 10: What was the best thing about the Transportation Wallet ............................. 37

Table 11: What would you change about the Transportation Wallet ............................. 40

Table 12: Mean final TW pre-paid Visa balances.......................................................... 42 


\section{Figures}

Figure 1 Affordable housing developments for TWRAH pilot program.......................... 12

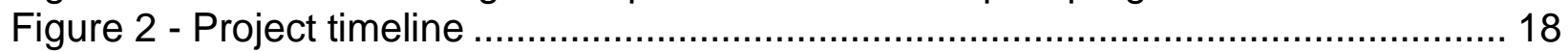

Figure 3 - Percentages of mode signed up and used by respondents with TWRAH

program.................................................................................................... 21

Figure 4 Mode usage (number of trips) difference among different types of TriMet pass holders ............................................................................................................... 23

Figure 5 - Trip purpose for each mode that respondents used with the TWRAH program

Figure 6 - Percentages of mode sign-up on the basis of the perception on whether TWRAH helped them use new mode(s) 29

Figure 7 - Percentages of mode usage (number of trips) on the basis of the perception of whether TWRAH helped them use new mode(s) 30 Figure 8 - The perception of whether TWRAH program helped participants with flexibility and opportunity to get to activities 31

Figure 9 - Participants' intention of using different modes after spending down TW money 32

Figure 10 - Mode usage by East Portland vs other participants 33

Figure 11 - Percentages of participant sign-ups by mode and their attendance of Transportation Fair

Figure 12 - Percentages of mode used by participants (number of trips) and their attendance of Transportation Fair 35

Figure 13 - Perception on the usefulness of Transportation Fairs

Figure 14 Word map of frequent responses to best thing about the TW.... 39 


\section{EXECUTIVE SUMMARY}

Low-income residents, immigrants, seniors, and people with disabilities - people who are often the most transport disadvantaged and thus stand to gain the most from tools that could reduce transportation costs and time - are often poorly served by new transportation tools and services, whether due to issues of affordability, gaps in technology adoption, unbanked populations, social or knowledge gaps, physical access, or other barriers. This study considers what aspects of new mobility appeal to various underserved groups, potential strategies to expand the reach and value of these transportation services, and how to implement programs to realize benefits.

The research team worked with the Portland Bureau of Transportation (PBOT) to evaluate the Transportation Wallet for Residents of Affordable Housing Pilot (TWRAH). The program provided a set of transportation incentives for low-income participants including a $\$ 308$ pre-paid US Bank Visa card which could be applied to public transit or other transportation services, a free bike share membership, and access to discounted rates on several services. We conducted a survey with the program's participants to understand how they used the Transportation Wallet (TW) and how the program helped them use different modes to get around.

The report covers findings from the evaluation, including whether the financial support of the program encouraged participants to use new mobility services (including Uber/Lyft, bike share, and e-scooter) that they had never used before; if the program increased access for participants, helping them make more trips and/or get to places they otherwise could not have gone; and the importance of personalized assistance in learning about and signing up for various mobility services and discounted fare programs.

The results indicate that a majority of these low-income participants were TriMet users. Nearly half of the respondents indicated that they tried to use new modes that they never used before with the TW, which was correlated with increased sign-ups and usage of ride-hail, e-scooter and bike share services. In addition, with this program, the participants appeared to use each mode more than they would have otherwise. These findings signify some level of effectiveness of this program in providing more mobility options and enhancing accessibility for low-income residents. The flexibility and convenience of this program were also highlighted in survey comments by participants regarding the payment method and scheduling time (for activities). Participants' survey responses also indicate that the program reduced stress related to how people might meet their basic travel needs or get around in the case of unexpected or emergency travel needs, all while reducing financial stress. The Transportation Fairs appeared to boost participants to sign-ups and use of transportation services, particularly new mobility services.

Although TriMet and ride-hail sign-ups and usage was highest among the available services, it is still notable that $28 \%$ to $29 \%$ of participants signed up for e-scooter and bike share services, even if many did not proceed to use the services. This highlights 
the potential of such a program, but also the need for programs to engage further on how to transition people from signing up for a service to actually using that service.

Input from participants suggests that several aspects can be improved. One would be to improve the way information about the program and new mobility usage is conveyed, specifically for those who never use phone apps to travel around. Another aspect would be to explore participants' experiences when using different services. For instance, safety concerns about bike share and e-scooter share services and age-related barriers (e.g., physical ability) were stressed by the participants in terms of the challenge of using these modes. This is consistent with previous studies about safety concerns as a barrier for using new mobility. Thus, transportation agencies may be limited in their promotion of these modes without further strategies to address perceptual and objective barriers in future programs. Other potential research for this program could be looking into the activity space (the area within which people travel or move during the course of their daily activities) of participants using different modes with TWRAH compared to the area when they did not have the TW so that we can gain more insights into the effect of the program on their travel behavior. 


\subsection{BACKGROUND}

Historically, transportation policies, plans, and projects have not met the needs of disadvantaged populations and have had adverse effects on their well-being (Corburn, 2009; Schweitzer \& Valenzuela, 2004). Although past research has shown that while lower-income households actually spend a lower percentage of their incomes on transportation (Blumenberg \& Agrawal, 2014), those dollars are coming out of much more constrained budgets and are thus subject to many more tradeoffs, which may come at the expense of economic opportunity, social inclusion, and personal well-being. Beyond the financial constraint, low-income populations are apt to face more travel burdens regarding the quality of transportation services (e.g., the frequency of transit), service availability, safety concerns, and payment methods.

Technological advances have opened up new mobility options such as ride-hailing (e.g., Uber, Lyft), car-sharing, (e.g., ReachNow, Zipcar), and micromobility (e.g., bike and escooter sharing), along with services such as ride-matching, online and mobile travel information and payment platforms, transforming how people conceptualize and navigate cities. These travel options and services offer the potential to connect people to jobs, healthcare, education and social opportunities on an efficient, on-demand basis. This could be especially important for those with fewer transportation options currently, including lower-income residents, immigrants and communities of color. However, in order for these potential benefits to be realized, people need to know about the available services and how to access them, as well as be able to physically access and afford the services. To make transportation options and services equitable, civic leaders should authentically engage with disadvantaged communities to understand their needs, give shared modes priority in planning and infrastructure, prioritize equitable service coverage, and plan for affordability (Cohen \& Cabansagan, 2017).

\subsection{TRANSPORTATION WALLET FOR RESIDENTS OF AFFORDABLE HOUSING}

The City of Portland's Bureau of Transportation (PBOT) established the Transportation Wallet (TW) program, a collection of passes and credits for use on transit, streetcar, bike share, and e-scooters, with the goal of reducing parking demand and congestion in parking districts by increasing the use of alternative modes, including transit and active transportation. Originally a transportation demand management (TDM) program tied to street parking fees in "Parking Districts," TWs are bundles of transportation credit (TriMet, Streetcar, BIKETOWN) that can be purchased by residents and employees of a district, or obtained by trading in a parking permit. Current districts include NW Parking District and Central Eastside Parking District.

In fall 2018 PBOT began planning for a TDM program to be utilized in affordable housing communities that would feature a TW element. The planning involved a needs assessment and preparation for program implementation. During this planning phase, PBOT identified the importance of involving social service and housing providers in 
delivering a program. In summer 2019, PBOT expanded the program/brand to include an Affordable Housing Pilot, that would bring a similar bundle of transportation credits to residents of affordable housing units in Portland. During the program planning phase, PBOT met with a number of social service and affordable housing providers. The central component of the TW for Residents of Affordable Housing (TWRAH) Pilot would be a pre-paid Visa card for $\$ 308$, which is equal to the cost of an annual TriMet reduced fare pass. They identified seven housing providers to move forward with for a program launch: Human Solutions, REACH CDC, Home Forward, Hacienda CDC, Catholic Charities, ROSE CDC, and Portland Community Reinvestment Initiatives Inc. (PCRI). Table 1 and Figure 1 describes and shows the main affordable housing locations for each housing provider. Not all of the housing buildings that we surveyed for this project are listed here, but they were generally near the locations shown on the map.

Table 1: Affordable housing organizations participating in the TWRAH pilot program

\begin{tabular}{|c|c|c|c|c|c|}
\hline $\begin{array}{c}\text { Housing } \\
\text { Organization }\end{array}$ & $\begin{array}{l}\text { Portland } \\
\text { Area }\end{array}$ & $\begin{array}{l}\text { TF } \\
\text { date }\end{array}$ & TF Site & $\begin{array}{l}\text { Other } \\
\text { residence } \\
\text { buildings }\end{array}$ & $\begin{array}{c}\text { Population } \\
\text { Characteristics }\end{array}$ \\
\hline $\begin{array}{l}\text { Portland } \\
\text { Community } \\
\text { Reinvestment } \\
\text { Inc. (PCRI) }\end{array}$ & $\begin{array}{l}\text { Inner } \\
\text { Northeast }\end{array}$ & $9 / 14 / 19$ & $\begin{array}{l}\text { Beatrice } \\
\text { Morrow }\end{array}$ & $\begin{array}{l}\text { Albina Plaza; } \\
\text { Park } \\
\text { Terrace; } \\
\text { Margaret } \\
\text { Carter Plaza }\end{array}$ & $\begin{array}{l}\text { Majority Black/African } \\
\text { American }\end{array}$ \\
\hline $\begin{array}{l}\text { Human } \\
\text { Solutions }\end{array}$ & Outer east & $8 / 9 / 19$ & Arbor Glen & & $\begin{array}{l}\text { Many very low income } \\
\text { and/or chronically } \\
\text { homeless }\end{array}$ \\
\hline Hacienda CDC & $\begin{array}{l}\text { Northeast / } \\
\text { Cully }\end{array}$ & 8/23/19 & $\begin{array}{l}\text { Villa de } \\
\text { Clara Vista }\end{array}$ & 4 others & $\begin{array}{l}\text { Many Latino/Somali } \\
\text { residents }\end{array}$ \\
\hline ROSE CDC & $\begin{array}{l}\text { Southeast } \\
\text { / 82nd }\end{array}$ & $8 / 29 / 19$ & $\begin{array}{l}\text { Orchards of } \\
\text { 82nd }\end{array}$ & & $\begin{array}{l}\text { Many families and } \\
\text { new mothers }\end{array}$ \\
\hline REACH CDC & $\begin{array}{l}\text { Downtown } \\
\text { / } \\
\text { Southwest }\end{array}$ & $8 / 13 / 19$ & $\begin{array}{l}\text { Gray's } \\
\text { Landing } \\
\text { Apartments }\end{array}$ & $\begin{array}{l}\text { Bronaugh } \\
\text { Apartments; } \\
\text { The Admiral }\end{array}$ & $\begin{array}{l}\text { Many residents who } \\
\text { are elderly and/or } \\
\text { disabled }\end{array}$ \\
\hline Home Forward & $\begin{array}{l}\text { Inner } \\
\text { Northeast / } \\
\text { Hollywood }\end{array}$ & $8 / 20 / 19$ & $\begin{array}{l}\text { Hollywood } \\
\text { East }\end{array}$ & & $\begin{array}{l}\text { Many residents who } \\
\text { are elderly and/or } \\
\text { disabled }\end{array}$ \\
\hline $\begin{array}{l}\text { Catholic } \\
\text { Charities of } \\
\text { Oregon }\end{array}$ & $\begin{array}{l}\text { Inner } \\
\text { Southeast } \\
\text { / Powell }\end{array}$ & 8/27/19 & Kateri Park & $\begin{array}{l}\text { Esperanza } \\
\text { Court; } \\
\text { Howard } \\
\text { House }\end{array}$ & $\begin{array}{l}\text { Many residents who } \\
\text { are elderly and/or } \\
\text { disabled, along with } \\
\text { many } \\
\text { immigrants/refugees }\end{array}$ \\
\hline
\end{tabular}




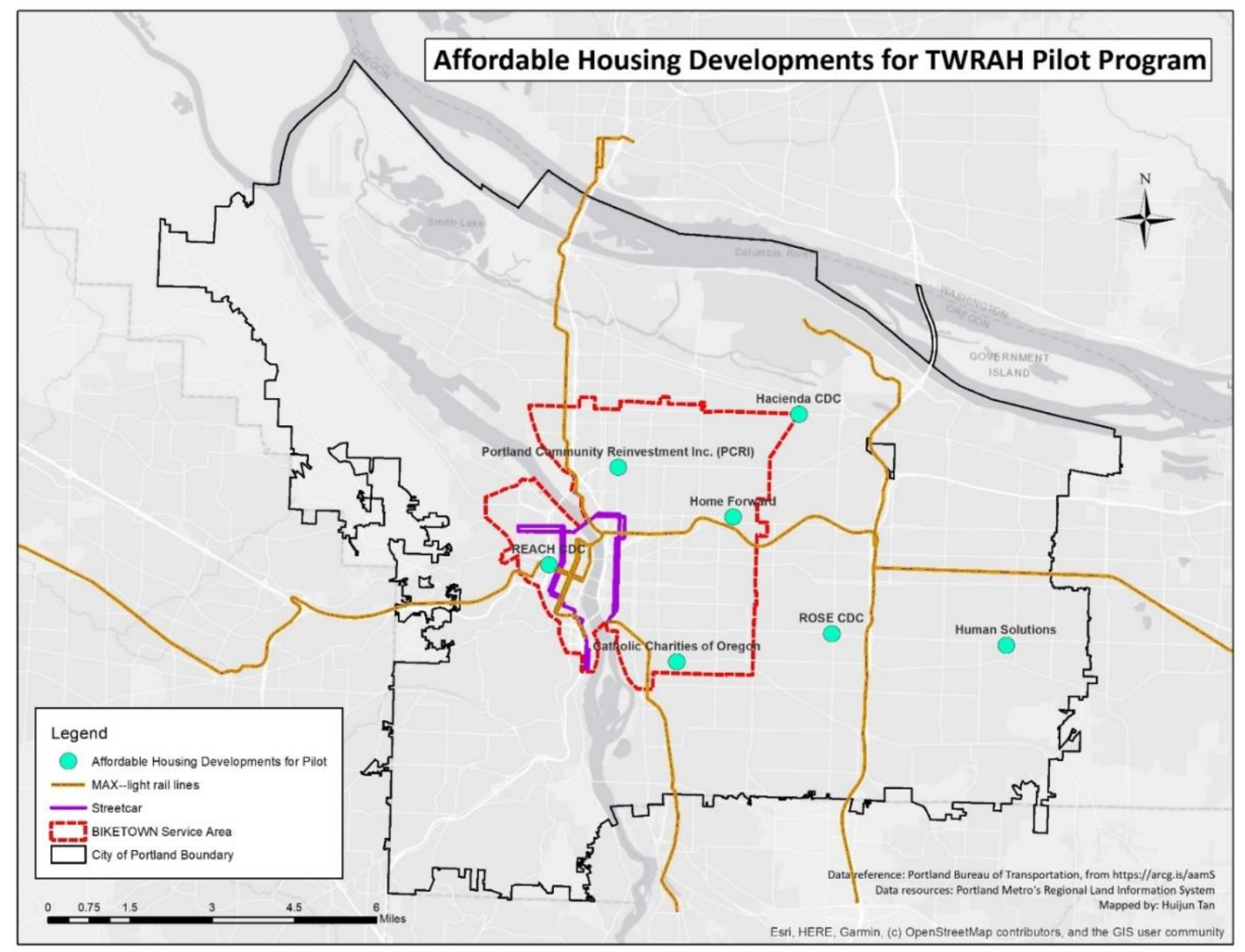

Figure 1 Affordable housing developments for TWRAH pilot program

\subsection{TWRAH COMPONENTS}

A primary component of the TWRAH was a $\$ 308$ US Bank prepaid Visa card, equal to the cost of an annual TriMet reduced fare pass, which was restricted for usage to transportation service providers, as defined by the providers' merchant category code. Other elements of the TWRAH included an annual bike share (BIKETOWN) membership at no cost, along with discounted e-scooter fares and small credits from service providers (e.g., $\$ 20$ to $\$ 25$ in credits for taxi, ride-hail, or car share use).

PBOT staff coordinated with housing resident coordinators and other partner staff to arrange a time and place in the residents' building to hold Transportation Fairs that connected residents to program information and hear from transportation service providers on how to access and use services. Residents could also sign-up for services and discounts, including a reduced fare TriMet program for low-income riders.

Only participants at the last fair received an active prepaid card, while other participants had cards that were activated later, or were later sent a card. Interested residents who did not attend a Transportation Fair were placed on a waitlist. After all seven fairs were completed, remaining prepaid cards were distributed to waitlist participants. About two- 
thirds of TW recipients attended a fair and signed up in person, while about one-third received a TW after being on the waitlist.

\subsection{TRANSPORTATION FAIRS}

In September of 2019 a series of Transportation Fairs (TF) were organized by PBOT, in which participants received assistance with enrollment in a discounted TriMet transit fare program and the opportunity to speak with representatives and sign up for other transportation services, such as bike share, e-scooter share, ride-hail (Uber/Lyft), taxi or car share services.

Transportation Wallets were distributed to 484 affordable housing residents in August and September 2019. Of these, about two-thirds of them enrolled in the TWRAH when they attended a TF. TriMet allowed all TF participants to automatically qualify for their low-income reduced fare, which offers either a $50 \%$ discount on per-ride fares, a $\$ 28$ monthly pass option, or a $\$ 308$ annual pass option. As noted above, residents of the participating housing providers who did not attend the TF were able to get on a waitlist, from which the remaining TWs were distributed.

\subsection{DATA COLLECTION AND RESEARCH OBJECTIVES}

PBOT conducted a pre-survey of participants upon enrollment at the TF to assess their transportation needs. PBOT collected 475 responses for the pre-survey. Our research team conducted post-surveys between April and September 2020 to assess the use of the TWRAH. We collected 278 responses, accounting for a $56 \%$ response rate. Besides the survey, we obtained data from PBOT regarding TriMet reduced fare pass registration among participants, which provide information about what type of transit pass participants purchased with the TW. We also interviewed resident coordinators, and prepared and hosted an implementation debrief session with representatives from housing providers, transportation services, and PBOT. Findings in this memo draw from the surveys, participation data, interviews, and debrief.

This study focuses on understanding how participants used the TW funds, the impact of the delivery mechanism, including the fairs, on program participation, how the program impacted participants lives, and on identifying ways that the program could be improved in future efforts. In particular the evaluation sought to answer the following key questions using the post-survey:

- How did participants use the TW (e.g., mode usage, trip purpose)?

- Did the program encourage participants to try new modes to get around?

- What were the effects of the individual support offered by the Transportation Fairs and the program implementation on participants' travel choices?

By answering these questions, we can have a better understanding of how transportation programs can improve the access to opportunities and enhance the multimodal travel pattern for low-income populations. In some cases, findings are broken out by specific housing provider, broad geography (e.g. East Portland vs other 
areas), or key demographic characteristics to provide a window into some variation in use of the program. Findings on programmatic delivery and potential improvements are also derived from debriefs and interviews with staff from the housing agencies, service providers, and PBOT.

\subsection{LITERATURE REVIEW}

Previous research shows that low-income populations face barriers in accessing essential goods, services, and opportunities, such as employment (Blumenberg \& Manville, 2004; Easley, 2018); healthy food (Clifton, 2004); health care services (Syed et al., 2013); and social networks (Cass et al., 2005), with adverse effects on their health and well-being. Interconnected with financial constraints, spatial mismatch (Kain, 1968) and mode mismatch (Blumenberg \& Manville, 2004; Fan, 2012) among lowincome groups, particularly minorities, exacerbate the challenge of their traveling through physical and social exclusion.

Even though low-income people are often considered to be transit-dependent, research also shows that these populations are increasingly dependent on automobiles to get around (Fan, 2012). However, reliance on private vehicles comes with another set of challenges. For low-income households, forced car ownership or car-related economic stress describes the financial anxiety associated with vehicle ownership and maintenance, leading to reduced spending in other essential areas (Blumenberg \& Agrawal, 2014; Mattioli \& Colleoni, 2016). In fact, apart from public transit and private vehicles, low-income households rely on a mix of transportation modes in order to gain access to jobs, food, and health care (Blumenberg \& Agrawal, 2014). Blumenberg and Agrawal found that low-income households do not travel more by multiple modes than middle- or high-income households, but their travel mix differs. Low-income household transportation packages are more diverse and are more likely to include transit and walking together ( $21 \%$ of trips) compared to high-income households ( $7 \%$ of trips). Even if low-income groups are inclined to use diverse travel packages, research found that low-income households use less transportation than they need or want, limiting access to destinations (Heinen \& Mattioli, 2019).

With the evolution and popularization of new mobility services (Uber/Lyft, bike share, escooter share, etc.) in our cities, some researchers have suggested that new mobility could meet the identified needs for travel disadvantaged populations provided that sufficient policy, regulations, and incentives are in place (Cohen \& Cabansagan, 2017; DeGood \& Schwartz, 2016). Moreover, new mobility options may also complement transit service by providing first mile-last mile connections to transit, which can expand access for travel disadvantaged populations (Boarnet et al., 2017). Integrated mobility (including shared mobility options and services) with integrated payment options is regarded as a strategy to encourage mobility for low-income populations. However, the barriers to accessing and using new mobility services among low-income groups can reinforce the problem of social inequality and exclusion. 


\subsection{THE BARRIERS FOR USING NEW MOBILITY}

Dillahunt and Veinot (2018) explored the low-income groups' barriers and facilitators associated with each form of transportation, which included individual capability facilitators and barriers (e.g., healthy enough to walk, digital literacy); interpersonal concerns (e.g., personal safety when walking); and affordability. They found that interpersonal forms of transportation were least problematic for individuals, although participants did express the need to reciprocate favors and the challenge of finding temporal matches for ride shares. Walking and ride-hailing were among the most challenging - the latter due to issues in affordability, interpersonal trust, digital literacy, trust in technology, and access to infrastructure (i.e., smartphones).

Several barriers and concerns have been highlighted when it comes to low-income populations' use of new mobility. Firstly, for lower-income people, the cost of new mobility options and services is a barrier to use. Covering the cost of service, generally a price-per-mile, may be challenging for some low-income residents (Dillahunt et al., 2017; Kodransky \& Lewenstein, 2014). In addition, registration for some new mobility options, such as car sharing and bike share, involve application fees and/or a lump sum fee for membership (Kodransky \& Lewenstein, 2014). Secondly, new mobility services require mobile technology for use, which presents another set of challenges for lowerincome residents. Younger people are more likely to use ride-hailing (Rayle et al., 2016), e-scooters (DeMeester et al., 2019), and have a greater degree of comfort with apps and technology (Golub et al., 2018). It may be more challenging to overcome the barriers associated with older adults and those with less digital literacy. While Golub et al. (21) found that users with less comfort with technology were willing to attend workshops at trusted institutions, only half of senior participants in Shirgaokar's study (2018) were interested in receiving training - of those, women were more receptive. Furthermore, apps need to be designed to address the visual and cognitive impairments associated with older adults, as well as individuals with impairments.

An additional challenge presented by mobile technology is the required bank or credit card for payment. Dillahunt and Veinot (2018) found that the credit card requirement was a challenge for some lower-income individuals in Michigan, who had to creatively work around the requirement in order to use Uber. Access to credit and debit continues to be a challenge for bike share (S. A. Shaheen et al., 2016). Cashless transit fare systems are also problematic for lower-income individuals who may only be able to pay in cash. For example, $40 \%$ of survey participants in Portland paid transit fares in cash, and the percentages were higher for low-income and people of color (Golub et al., 2018). Prepaid mobility packages can be an option to tackle this issue. One study found that transit riders who buy multimodal prepay travel cards were more likely to be those who needed to transfer, have lower incomes, were younger, and were daily transit riders (Graham \& Mulley, 2012). The characteristics of those who purchased the multimodal card closely resembled those who had previously paid cash, suggesting that the introduction of a multimodal prepay ticket attracted previous cash users. Another study found that, without a multimodal ticket option, transit riders were more likely to pay cash than a mode-specific prepay option (Wardman \& Hine, 2000). Besides the 
challenges of technology, payment methods and affordability, safety concerns and uneasy attitudes about use may discourage low-income people from using ride-hailing, bike share or e-scooter share (Fedorowicz et al., 2020; McNeil et al., 2017).

\subsection{TRANSPORTATION PROGRAMS FOR LOW-INCOME GROUPS}

Programs that offer reduced transit fares, transit passes, or other forms of transportation incentives are designed to reduce the burden of transportation costs for vulnerable populations. Many transit agencies offer reduced fare or free ride programs for students, Medicare recipients, adults over 65 years old, and people with disabilities-the latter two being federally mandated. Fewer transit agencies offer reduced fares for lowincome riders (ACEEE, 2019; Thistle \& Paget-Seekins, 2017). TriMet, the transit agency serving the Portland metropolitan area, provides fares at half the price for low-income individuals and fare relief programs to nonprofit organizations serving low-income populations (TriMet, 2019). Lifeline Transportation Program, funded by a Metropolitan Transportation Commission grant, provides bus passes and tickets for CalWORKS recipients for employment and health care purposes. The program also offers taxi vouchers for transportation emergencies related to employment and support services. According to the 2010 Lifeline Transportation Program Quarterly Report, 179 individuals were able to search and retain employment and participate in training as a result of using bus passes or tickets (Sandstrom, 2010). Recently, some cities have actively incorporated equity into the implementation of new mobility programs. The City of Seattle uses permit fees to increase the number of adaptive bikes (Shaheen \& Cohen, 2019). Cities also work on payment options, such as purchasing ride passes through convenience stores or reserve rides by SMS text, or using public transportation passes as a form of payment for other modes (Fedorowicz et al., 2020). The District of Columbia requires bike share companies to offer a cash payment option (Shaheen \& Cohen, 2019).

Beyond subsidies and payment methods, conducting outreach and engagement to lowincome populations to understand their perceptions of new mobility services and inform them how different shared mobility companies operate could potentially encourage the use of new mobility (Fedorowicz et al., 2020). The City of Oakland hosted an outreach program named "aided/enable events" for OakDOT's Share Mobility initiative (City of Oakland, 2018). The outreach included free training workshops and adult classes (via partnering with the David E. Glover Education \& Technology Center), with primarily older adult participants who have little computer knowledge. Participants were encouraged to download mobility apps and sign up for accounts when the staff were physically present and able to assist. The Bay Area Metropolitan Transportation Commission and Ford GoBike/Motivate funded eight community organizations to conduct equity outreach about discounted bike share memberships (Bike Share for All or BS4A) and other bike resources in low-income neighborhoods. After 12,300 face-toface contacts and 3,040 hours of outreach, BS4A accounts for $20 \%$ of Ford GoBike memberships, and 80,460 total trips have been taken by BS4A members since the program was launched (TransForm, 2018). 


\subsection{METHODS}

\subsection{DATA COLLECTION}

Upon arrival at the Transportation Fairs, participants were asked to take the "presurvey." The survey asked about mode and frequency for typical commute and noncommute trips, common barriers to different modes, and a few basic demographic questions. The survey was designed to be taken quickly upon intake at the fairs.

Representatives from PBOT and the housing providers were on hand to assist in filling out the survey. Ad hoc translation and interpretation services from housing agencies and PBOT were available on-site. Waitlist participants were provided surveys by housing providers. The pre-survey assesses what transportation options people had available to them and what types of trips they were making. Transportation Wallets were distributed to 484 residents in August and September 2019, and PBOT collected 475 responses for the pre-survey.

Our research team conducted post-surveys between April and September 2020 to assess the use of the TWRAH. The post-surveys included sections on the participants' experience at the Transportation Fair, overall TWRAH impressions (best aspect, things they would change, perceived mode changes), a set of questions about key travel services such as TriMet, ridehail, taxis, bike share, and e-scooters, along with some more detailed household and demographic questions. Draft surveys were developed by the research team, and shared with the PBOT TWRAH team and housing provider resident coordinators for review and feedback, after which revisions were made to clarify and simplify some survey questions. Paper and online versions of the survey were developed.

Given the COVID-19 pandemic since March 2020, surveys were conducted over the phone and online rather than in person, using contact information participants provided upon sign-up. For those participants without either phone or email contact information, we mailed flyers to their home addresses to notify them that they could take the survey online or over the phone. PBOT provided interpretation services over the phone for participants lacking English proficiency. We collected 278 responses, accounting for a $56 \%$ response rate. Besides the survey, we obtained data from PBOT regarding TriMet reduced fare pass registration among participants, which provide information about what type of transit pass participants purchased with the TW. The analysis in this paper relies primarily on the post-survey, but is supplemented with pre-survey and card use data from PBOT. We present results mainly through descriptive analysis.

As part of the development of the surveys and in documenting the TWRAH process, the research team conducted interviews with the housing organization resident coordinators. The interviews helped us to understand the populations at each of the buildings and plan for their potential survey needs. The research team also hosted a debrief after the Transportation Fairs with resident coordinators, service providers and the PBOT TWRAH team. Topics covered in the debrief included feedback about 
residents' experiences at the fairs, use of the TWs, ongoing support needed for residents, and how each organization/service provider experienced the fairs.

Figure 2 shows the project timeline.

\section{Timeline for Project Implementation}

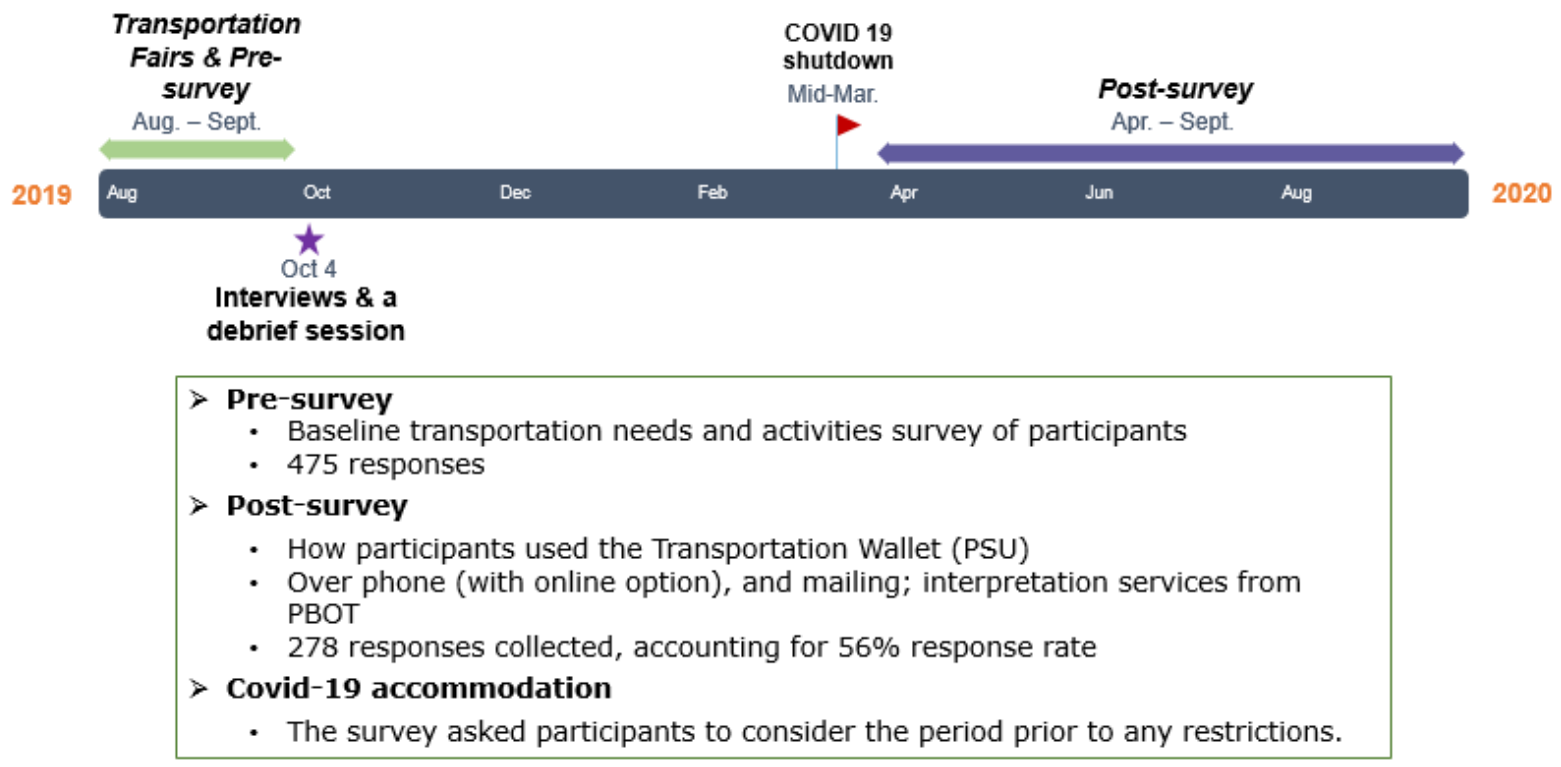

Figure 2 - Project timeline 


\subsection{RESULTS AND FINDINGS}

\subsection{BACKGROUND AND DEMOGRAPHICS OF PARTICIPANTS}

Table 2 shows socioeconomic demographics information of survey respondents. In the post-survey, there were $41 \%$ White non-Hispanic and 59\% Black, Indigenous or and other People of Color (BIPOC) respondents, compared to $36 \%$ White non-Hispanic and $64 \% \mathrm{BIPOC}$ in the pre-survey. In terms of age, $65 \%$ of post-survey respondents were between 35 and 64 years old, compared to $58 \%$ in the pre-survey. Respondent educational attainment, gender, and home language were roughly comparable in the pre- and post-surveys, with about $78-79 \%$ with less than a college degree in each, 64$65 \%$ of respondents were female in each, and $23 \%$ to $26 \%$ did not speak English at home. In the post-survey, we also asked other questions relevant to respondents' socioeconomic status. Regarding employment status, $59 \%$ of respondents were not currently employed.

Table 2: Social-demographics of the participants

\begin{tabular}{|c|c|c|}
\hline & $\begin{array}{c}\text { Pre-survey (475 } \\
\text { total) }\end{array}$ & $\begin{array}{c}\text { Post-survey (278 } \\
\text { total) }\end{array}$ \\
\hline & $\%$ & $\%$ \\
\hline \multicolumn{3}{|l|}{ Race } \\
\hline White & $36 \%$ & $41 \%$ \\
\hline Latino/Hispanic & $17 \%$ & $16 \%$ \\
\hline Black/African American & $28 \%$ & $24 \%$ \\
\hline Asian & $9 \%$ & $8 \%$ \\
\hline Native American/Alaska Native & $3 \%$ & $6 \%$ \\
\hline Native Hawaiian/Pacific Islanders & $1 \%$ & $0 \%$ \\
\hline Other & $6 \%$ & $5 \%$ \\
\hline$n$ & 320 & 262 \\
\hline \multicolumn{3}{|l|}{ Age } \\
\hline 18 to 24 & $8 \%$ & $4 \%$ \\
\hline 25 to 34 & $18 \%$ & $17 \%$ \\
\hline 35 to 44 & $16 \%$ & $18 \%$ \\
\hline 45 to 54 & $22 \%$ & $23 \%$ \\
\hline 55 to 64 & $20 \%$ & $24 \%$ \\
\hline $65+$ & $16 \%$ & $14 \%$ \\
\hline $\mathrm{n}$ & 432 & 264 \\
\hline \multicolumn{3}{|l|}{ Education } \\
\hline High school degree or less & $45 \%$ & $43 \%$ \\
\hline $\begin{array}{l}\text { Some college/technical/ } \\
\text { Community College/two-year degree }\end{array}$ & $33 \%$ & $36 \%$ \\
\hline College degree/four-year degree & $11 \%$ & $12 \%$ \\
\hline Post graduate & $5 \%$ & $2 \%$ \\
\hline Prefer not to disclose & $6 \%$ & $7 \%$ \\
\hline $\mathrm{n}$ & 376 & 270 \\
\hline \multicolumn{3}{|l|}{ Gender } \\
\hline Female & $65 \%$ & $64 \%$ \\
\hline
\end{tabular}




\begin{tabular}{|c|c|c|}
\hline & $\begin{array}{c}\text { Pre-survey (475 } \\
\text { total) }\end{array}$ & $\begin{array}{c}\text { Post-survey (278 } \\
\text { total) }\end{array}$ \\
\hline Male & $34 \%$ & $35 \%$ \\
\hline Non-binary & $1 \%$ & $0.4 \%$ \\
\hline $\mathrm{n}$ & 436 & 269 \\
\hline \multicolumn{3}{|l|}{ Language } \\
\hline Do not speak English at home & $26 \%$ & $23 \%$ \\
\hline Only speak English at home & $64 \%$ & $64 \%$ \\
\hline Speak English and other languages & $10 \%$ & $13 \%$ \\
\hline $\mathrm{n}$ & 414 & 272 \\
\hline \multicolumn{3}{|l|}{ Employment } \\
\hline Not currently working & $n / a$ & $59 \%$ \\
\hline $\mathrm{n}$ & & 278 \\
\hline \multicolumn{3}{|l|}{ Household Size } \\
\hline Adult (Average) & $\mathrm{n} / \mathbf{a}$ & 1.6 \\
\hline Child (Average) & $\mathrm{n} / \mathrm{a}$ & 1.4 \\
\hline $\mathrm{n}$ & & $\begin{array}{c}262 \text { (148 for hh with } \\
\text { children) }\end{array}$ \\
\hline \multicolumn{3}{|l|}{ Income } \\
\hline Less than $\$ 15,000$ & $\mathbf{n} / \mathbf{a}$ & $68 \%$ \\
\hline$\$ 15,000-\$ 24,999$ & $\mathrm{n} / \mathbf{a}$ & $19 \%$ \\
\hline$\$ 25,000-\$ 34,999$ & n/a & $9 \%$ \\
\hline$\$ 34,000-\$ 74,999$ & $\mathrm{n} / \mathbf{a}$ & $4 \%$ \\
\hline $\mathrm{n}$ & & 245 \\
\hline
\end{tabular}

Table 3 shows participants' characteristics related to vehicle availability and access to smartphones, which are important for using many features of various mobility services. Only $29 \%$ of the respondents owned or leased a car, though nearly half had a driver's license (47\%). In addition, $80 \%$ of them had a smartphone with a data plan.

Table 3: Participant mobility and access questions

\begin{tabular}{|c|c|c|}
\hline & \multicolumn{2}{|c|}{ Post-survey } \\
\hline & $\%$ & $\mathrm{n}$ \\
\hline \multicolumn{3}{|l|}{ Vehicle ownership (or Lease) } \\
\hline No & $71 \%$ & 269 \\
\hline \multicolumn{3}{|l|}{ Driver's license } \\
\hline No & $53 \%$ & 269 \\
\hline \multicolumn{3}{|l|}{ Smartphone ownership } \\
\hline Yes, with a data plan & $80 \%$ & \multirow{4}{*}{253} \\
\hline Yes, with cell/text service only & $7 \%$ & \\
\hline No, just a flip phone & $11 \%$ & \\
\hline No cell phone & $2 \%$ & \\
\hline
\end{tabular}

\subsection{THE TRANSPORTATION WALLET AND SERVICES/MODES USED}

This section presents the services participants signed up for and how they spent TW funds. Figure 3 shows the percentage of respondents who signed up for each transportation service with the TW, and the number of trips for each mode since they enrolled in the TWRAH. Overall, the percentages of respondents who signed up for a 
TriMet reduced fare pass (74\%) and Uber or Lyft service (59\%) (either signed up at the fair or some other time) were higher than the percentages of those who signed up for bike share (29\%) and e-scooter share (28\%) services. In regard to the mode usage, $90 \%$ of respondents used the TW on TriMet services. Over half of respondents (52\%) used Uber or Lyft and $31 \%$ of them used taxi services, compared to $12 \%$ for bike share and $15 \%$ for e-scooters. These results reflect that the TWRAH substantially helped participants use TriMet (including bus, MAX, streetcar). For other services, including Uber or Lyft, bike share, and e-scooter services, sign-up percentages were considerably higher than usage. Overall, $91 \%$ of those who signed up for a TriMet discounted pass reported using TriMet with the TW. For Uber or Lyft, $80 \%$ of those who signed up used the service; those numbers were $36 \%$ for bike share, and $45 \%$ for e-scooters. A further understanding of this gap may help the transportation agency to improve the usage of these new mobility services among participants.

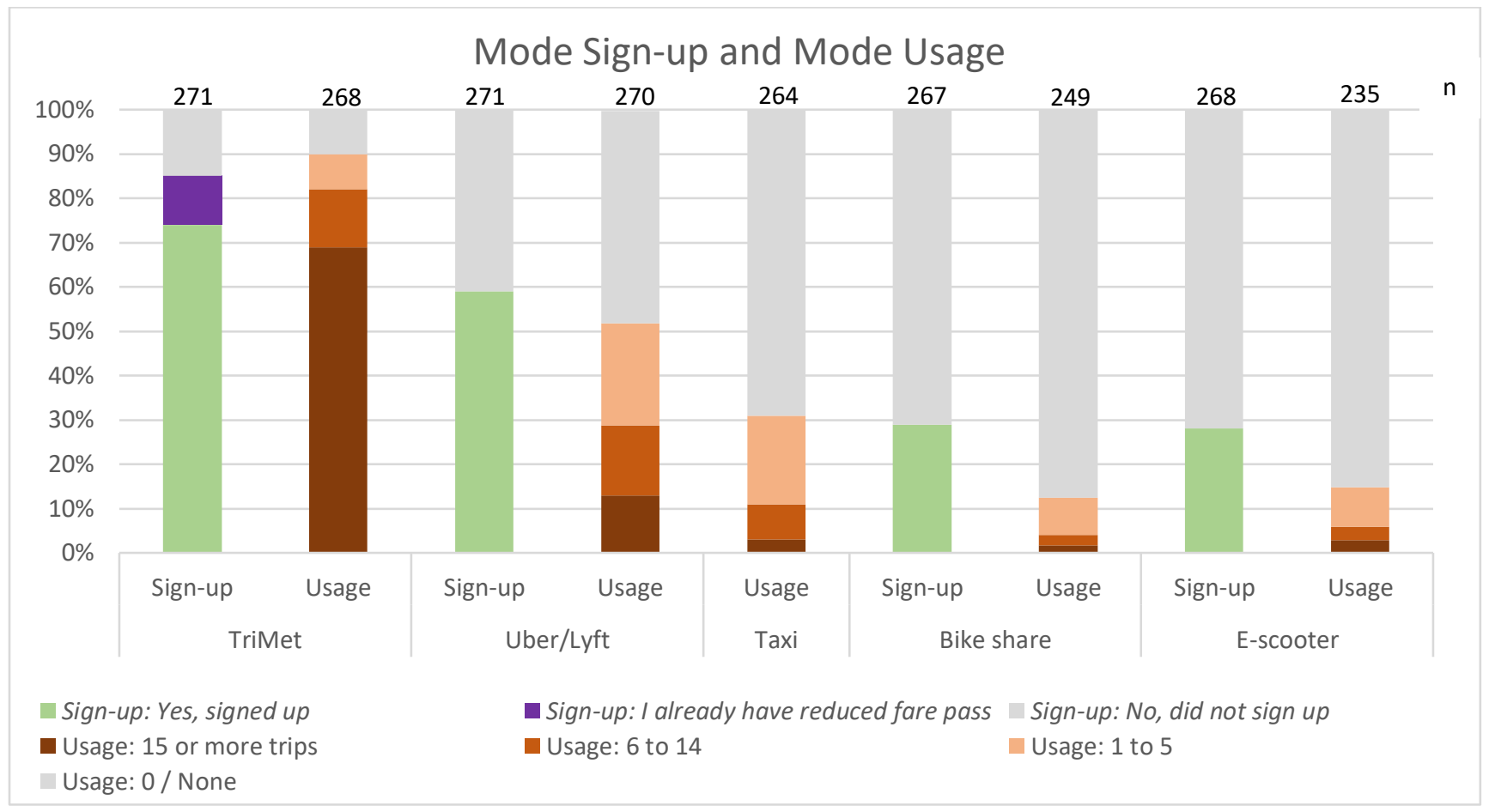

Figure 3 - Percentages of mode signed up and used by respondents with TWRAH program

\subsubsection{TriMet Transit Sign-ups and Usage}

According to data from the post-survey and PBOT, $20 \%$ of respondents chose to sign up for an annual reduced fare pass ( $\$ 308$, or the full value of TW); $11 \%$ for monthly reduced fare pass ( $\$ 28$ per month); and 53\% for regular reduced fare pass (pay-perride at $50 \%$ off), while $17 \%$ did not sign up for a reduced fare pass. Participants' mode use with the TW is shown in Figure 3, broken down by which TriMet option they chose. 
As expected, TriMet usage was high among those who chose the annual or monthly pass option. All respondents with annual reduced fare passes, and $97 \%$ of those with a monthly pass, used TriMet at least once, compared to $87 \%$ of those without either a monthly or annual pass. The frequency of TriMet use was somewhat higher among annual pass holders, with $80 \%$ indicating that they used the TW to take TriMet 25 or more times, compared to $61 \%$ for monthly pass holders, and $50-53 \%$ for others, with the difference between annual pass holders being significant from those without a monthly or annual pass (Pearson Chi-Square with z-test, $p<0.05$ ). However, among respondents who chose the annual fare pass, use of other services was limited. Annual pass holders' use of Uber or Lyft (19\%), taxis (15\%), and e-scooters (2\%) were lower than respondents with monthly TriMet passes $(58 \%, 30 \%, 11 \%$, respectively) and those without either of the passes $(62 \%, 38 \%, 18 \%)$. The differences were significant between annual pass holders and all others for Uber or Lyft (Pearson Chi-Square with z-test, $p<0.001)$. Since the annual pass used up the entire TW allotment, participants who purchased this type of pass were less likely to use most other transportation services, even though some offered discounts or small credits (e.g., a \$25 sign-up bonus) on top of any TW amounts, along with a free bike share membership. While those who did not sign up for a TriMet reduced fare pass used e-scooter service $(20 \%)$ more than other types of pass holders, they also were likely to use TriMet frequently, with $80 \%$ using the TW for TriMet at least once.

Comparing the results in Figure 4 with the results from the pre-survey about each group's frequency of TriMet use before the TWRAH, we found that those who purchased the TriMet annual pass with the TW reported that, before the program, they were already using TriMet more frequently $(68 \%$ said they used TriMet five or more days per week) than other TriMet pass holders (monthly pass holders, 50\%; regular reduced fare pass holders, $54 \%$; non-reduced fare pass holders, $59 \%$ ). This result indicates that people who were frequent TriMet riders before TWRAH were more likely to choose the annual pass option with the TW. 


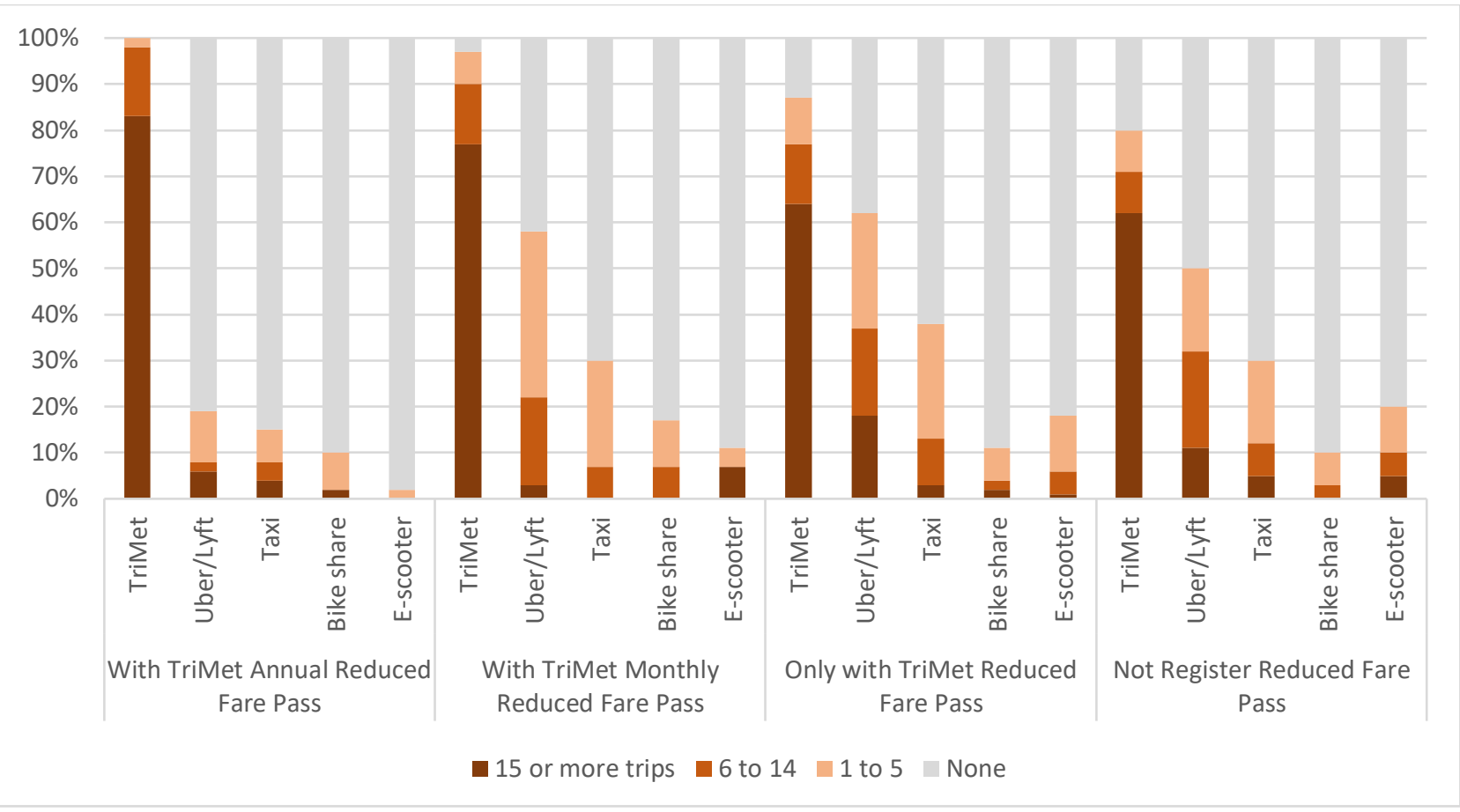

Figure 4 Mode usage (number of trips) difference among different types of TriMet pass holders

Participants were most likely to sign up for and use their TW credit on TriMet (see Table 4). Overall, $83 \%$ of the participants surveyed signed up for the TriMet reduced fare program, of whom $19 \%$ signed up for an annual pass; $11 \%$ signed up to have $\$ 28$ deducted monthly (value of a monthly pass); and 53\% enrolled but did not sign up for an annual pass or monthly deduction. Of the $19 \%$ who signed up for annual unlimited passes, which consumed the entirety of their $\$ 308$ TW funds, most were from one of three housing providers - Catholic Charities, Hacienda CDC, and Home Forward. Men were somewhat more likely to sign up for the annual pass (28\% compared to $16 \%$ for women), and participants with a home language other than English were more likely to sign up for the annual pass (30\% compared to $22 \%$ of multiple language homes and $16 \%$ of English-only homes). Older participants were also more likely to sign up for the annual pass, with over $30 \%$ of those over 55 compared to less than $15 \%$ of all younger age groups.

People who signed up for the annual TriMet pass were indeed more likely to use TriMet frequently, with $80 \%$ of those respondents telling us that they used TriMet " 25 or more times" (compared to $58 \%$ of all respondents). Annual pass holders were also much less likely to use Uber or Lyft, taxis or e-scooters, which is expected as they would have exhausted their TW on the annual pass. We did not observe any difference in BIKETOWN usage based on TriMet pass selection, with around $11 \%$ of participants trying the bike share service regardless of TriMet pass type, which is not surprising since TW funds were not needed to use BIKETOWN. 
Table 4: Enrollment in TriMet reduced fare program

\begin{tabular}{lccccc} 
& $\begin{array}{c}\text { Reduced fare } \\
\text { - Annual } \\
\text { Pass }\end{array}$ & $\begin{array}{c}\text { Reduced fare - } \\
\text { Monthly Pass }\end{array}$ & $\begin{array}{c}\text { Enrolled in } \\
\text { reduced fare } \\
\text { program }\end{array}$ & $\begin{array}{c}\text { Did not enroll in } \\
\text { reduced fare } \\
\text { program }\end{array}$ & $\mathbf{n}$ \\
\hline Catholic Charities & $26 \%$ & $14 \%$ & $47 \%$ & $14 \%$ & 43 \\
\hline Home Forward & $30 \%$ & $9 \%$ & $45 \%$ & $16 \%$ & 74 \\
\hline PCRI Inc. & $11 \%$ & $8 \%$ & $49 \%$ & $32 \%$ & 37 \\
\hline REACH CDC & $13 \%$ & $18 \%$ & $67 \%$ & $3 \%$ & 39 \\
\hline Hacienda CDC & $26 \%$ & $2 \%$ & $51 \%$ & $21 \%$ & 47 \\
\hline Human Solutions & $0 \%$ & $32 \%$ & $64 \%$ & $5 \%$ & 22 \\
\hline Rose CDC & $0 \%$ & $0 \%$ & $73 \%$ & $27 \%$ & 15 \\
\hline All & $19 \%$ & $11 \%$ & $53 \%$ & $17 \%$ & 277 \\
\hline
\end{tabular}

Percentages show respondent breakdown within each housing organization. Shaded rows are primarily East Portland locations

Table 5: TriMet use

How many trips did you take on TriMet using the Transportation Wallet (annual pass / HOP card)?

\begin{tabular}{lcccccc}
\hline & $\mathbf{n}$ & $\mathbf{0} /$ None & $\mathbf{1}$ to $\mathbf{5}$ & $\mathbf{6}$ to $\mathbf{1 4}$ & $\mathbf{1 5}$ to $\mathbf{2 4}$ & $\begin{array}{c}\mathbf{2 5} \text { or } \\
\text { more }\end{array}$ \\
\hline Catholic Charities & 43 & $5 \%$ & $2 \%$ & $14 \%$ & $19 \%$ & $60 \%$ \\
\hline Home Forward & 74 & $3 \%$ & $7 \%$ & $15 \%$ & $4 \%$ & $72 \%$ \\
\hline PCRI Inc. & 37 & $22 \%$ & $8 \%$ & $5 \%$ & $11 \%$ & $54 \%$ \\
\hline REACH CDC & 39 & $5 \%$ & $11 \%$ & $8 \%$ & $21 \%$ & $55 \%$ \\
\hline Hacienda CDC & 47 & $11 \%$ & $11 \%$ & $13 \%$ & $15 \%$ & $51 \%$ \\
Human Solutions & 22 & $23 \%$ & $9 \%$ & $5 \%$ & $18 \%$ & $45 \%$ \\
\hline Rose CDC & 15 & $31 \%$ & $8 \%$ & $15 \%$ & $8 \%$ & $38 \%$ \\
\hline All & 277 & $10 \%$ & $8 \%$ & $11 \%$ & $13 \%$ & $58 \%$ \\
\hline
\end{tabular}

Percentages show respondent breakdown within each housing organization. Shaded rows are primarily East Portland locations

\subsubsection{Sign-up and Usage of Other Transportation Services}

The percentage of respondents signing up for ride-hail, BIKETOWN (bike share), and escooters at the fair and the percentage of respondents who used each type of service are shown in Table 6 and Table 7, respectively. Summaries for each type of service are provided below. 
Table 6: Percentage of respondents signing up for ride-hail, BIKETOWN, and e-scooters at the fair

\begin{tabular}{lcccc} 
& Ride-hail & BIKETOWN & E-Scooters & $\mathbf{n}$ \\
\hline Catholic Charities & $23 \%$ & $12 \%$ & $14 \%$ & 43 \\
\hline Home Forward & $30 \%$ & $21 \%$ & $21 \%$ & 74 \\
\hline PCRI Inc. & $38 \%$ & $19 \%$ & $27 \%$ & 37 \\
\hline REACH CDC & $51 \%$ & $36 \%$ & $41 \%$ & 39 \\
\hline Hacienda CDC & $55 \%$ & $22 \%$ & $13 \%$ & 47 \\
Human Solutions & $68 \%$ & $18 \%$ & $27 \%$ & 22 \\
\hline Rose CDC & $92 \%$ & $58 \%$ & $58 \%$ & 15 \\
\hline Total & $43 \%$ & $23 \%$ & $24 \%$ & 277
\end{tabular}

Percentages show respondent breakdown within each housing organization. Shaded rows are primarily East Portland locations

Table 7: Percentage of respondents who used each type of service

\begin{tabular}{|c|c|c|c|c|c|c|c|c|c|c|c|}
\hline & \multicolumn{3}{|c|}{ TriMet } & \multicolumn{2}{|c|}{ Ride-hail } & \multicolumn{2}{|c|}{ Taxi } & \multicolumn{2}{|c|}{ BIKETOWN } & \multicolumn{2}{|c|}{ E-scooters } \\
\hline & $\mathrm{n}$ & Used & $\begin{array}{l}25+ \\
\text { trips }\end{array}$ & Used & $\begin{array}{l}25+ \\
\text { trips }\end{array}$ & Used & $\begin{array}{l}25+ \\
\text { trips }\end{array}$ & Used & $\begin{array}{l}25+ \\
\text { trips }\end{array}$ & Used & $\begin{array}{l}25+ \\
\text { trips }\end{array}$ \\
\hline Catholic Charities & 43 & $95 \%$ & $60 \%$ & $47 \%$ & $9 \%$ & $21 \%$ & $2 \%$ & $12 \%$ & $5 \%$ & $10 \%$ & $0 \%$ \\
\hline Home Forward & 74 & $97 \%$ & $72 \%$ & $30 \%$ & $5 \%$ & $42 \%$ & $3 \%$ & $7 \%$ & $0 \%$ & $11 \%$ & $2 \%$ \\
\hline PCRI Inc. & 37 & $78 \%$ & $54 \%$ & $59 \%$ & $14 \%$ & $49 \%$ & $5 \%$ & $14 \%$ & $0 \%$ & $17 \%$ & $0 \%$ \\
\hline REACH CDC & 39 & $95 \%$ & $55 \%$ & $51 \%$ & $0 \%$ & $36 \%$ & $0 \%$ & $11 \%$ & $3 \%$ & $20 \%$ & $0 \%$ \\
\hline Hacienda CDC & 47 & $89 \%$ & $51 \%$ & $60 \%$ & $2 \%$ & $13 \%$ & $0 \%$ & $19 \%$ & $0 \%$ & $14 \%$ & $0 \%$ \\
\hline Human Solutions & 22 & $77 \%$ & $45 \%$ & $82 \%$ & $14 \%$ & $15 \%$ & $0 \%$ & $10 \%$ & $0 \%$ & $22 \%$ & $6 \%$ \\
\hline Rose CDC & 15 & $69 \%$ & $38 \%$ & $77 \%$ & $15 \%$ & $33 \%$ & $0 \%$ & $9 \%$ & $0 \%$ & $18 \%$ & $0 \%$ \\
\hline Total & 277 & $90 \%$ & $58 \%$ & $51 \%$ & $7 \%$ & $31 \%$ & $2 \%$ & $11 \%$ & $1 \%$ & $15 \%$ & $1 \%$ \\
\hline
\end{tabular}

Percentages show respondent breakdown within each housing organization. Shaded rows are primarily East Portland locations

\section{Ride-hail}

After TriMet, the next most frequent service signed up for was ride-hail (either Uber or Lyft), with $43 \%$ signing up for one or both ride-hail services at the TF (and an additional $17 \%$ telling us they signed up at some other point). Women were more likely to sign up for a ride-hail service than men ( $48 \%$ of women did so, compared to $33 \%$ of men). NonEnglish speakers were somewhat less likely to have signed up for ride-hail ( $36 \%$ compared to $45-47 \%$ ), and younger participants were more likely to sign up for ride-hail (68-70\% of those under 35 signed up, compared to $24-32 \%$ of those over 55 years old). Just over half of the participants stated they used Uber or Lyft with the TW, with participants from predominately East Portland locations (Human Solutions at $82 \%$, Rose CDC at $77 \%$ and Hacienda CDC at $60 \%$ ) being the most likely to use them. Women were more likely than men to use ride-hail ( $56 \%$ compared to $43 \%$ ). Younger participants were also more likely to use ride-hail. 


\section{Taxis}

Although we don't have data on taxi service sign-ups, about $31 \%$ of participants stated that they used their TW on taxi trips. Participants from PCRI (49\%) and Home Forward $(42 \%)$ were most likely to take taxi trips. Participants at the East Portland locations were less likely to report making taxi trips using their TW funds. Older participants were also a bit more likely to use the TW for taxi trips than younger participants.

\section{BIKETOWN}

Twenty-three percent signed up for BIKETOWN at the TF, with an additional $6 \%$ signing up at some other time. Non-English speakers were less likely to sign up for BIKETOWN (17\% compared to $24-28 \%$ for others). Younger participants were also more likely to sign up for BIKETOWN, with $40 \%$ of those under 35 signing up, $23-27 \%$ of those 35 to 54 years of age, and $11-16 \%$ of those 55 years or older. Of the $29 \%$ who indicated that they signed up for BIKETOWN at the TF or at some point, only $11 \%$ stated they actually made a trip with BIKETOWN. Hacienda residents were most likely to use BIKETOWN, with $19 \%$ of their participants taking trips. About $20 \%$ of participants under 45 used BIKETOWN, compared to $12 \%$ of those 45 to 54 and only $3 \%$ of those 55 and older.

\section{E-Scooters}

Just under a quarter (24\%) of participants signed up for an e-scooter service at the TF, along with $4 \%$ signing up for an e-scooter service at some other time. Participants who only spoke English at home were much more likely to sign up (31\% compared to 11 $12 \%$ of other respondents). Younger respondents were much more likely to sign up as well, with $60 \%$ of those 18 to 24 signing up for at least one e-scooter service, with signups dropping off quickly for older users. About $15 \%$ of participants indicated that they had taken at least one e-scooter trip using their TW. Men were more likely than women to take e-scooter trips (22\% to 10\%), and younger participants were more likely to take such trips, including $33 \%$ of those aged 18-24.

\subsubsection{Trip Purposes/Types by Service}

For each mode, participants were asked what types of trips they took. Table 8 and Figure 5 illustrate the percentage of respondents indicating that they used a mode/service for a given trip purpose category (among those who used each mode). Note that for BIKETOWN and e-scooter trips, participants were given the option to select "fun/no destination" or "exercise" as response options, while these options were not provided for other services.

Shopping (e.g., grocery shopping) and errand trips were the most frequent trip type for people who reported taking trips with the TW on TriMet $(87 \%$ of those who reported trips on TriMet reported this trip purpose at least once), Uber/Lyft (49\%) and taxi (46\%). Forty percent of e-scooter users also reported shopping and errand trips. For bike share 
and e-scooter usage, recreation and exercise were the primary trip purposes. TriMet $(72 \%)$ and taxi (26\%) played an important role in helping respondents go to or from medical appointments.

Interestingly, the percentages of work/school and work-related trips for TriMet users were similar to the ones for Uber/Lyft users. However, based on other feedback provided in the survey, and the relative cost structures of the services, it is logical to conclude that TriMet was more of a daily work mode, with ride-hail serving as more of a means of making one-off type trips, perhaps due to unexpected travel needs, unusual travel times, etc. For social/recreation/dining trips, over $60 \%$ of participants used TriMet, over $40 \%$ used Uber and Lyft, and around $30 \%$ to $40 \%$ used taxis, bike share and escooters. These findings could be useful for consideration when developing programs and targeting particular trip types.

The various trip types by mode or service provide insight into how programs designed to engage participants in new mobility options might target or conceptualize each option, as well as areas that might need further engagement if they are to fill a particular need or encourage new users. For example, Uber/Lyft and taxis are more likely to be used for errands or social trips, while bike share and e-scooters are more likely to be used for fun or exercise. Each of these trip types could be emphasized as benefits of these modes. However, these modes also have been used by some people for work/school or work-related trips, which could be further explored for potential encouragement programs.

Table 8: Percentage of respondents reporting each trip purpose, by each type of service To/from Other Social / work / work Med. Shopping Rec./ Fun / no school trips Appts. / Errands Dining dest. Exercise Other $\mathrm{n}$

\begin{tabular}{llllllllll} 
& school & trips & Appts. & / Errands & Dining & dest. & Exercise & Other & n \\
\hline TriMet & $41 \%$ & $31 \%$ & $72 \%$ & $87 \%$ & $65 \%$ & n/a & n/a & $10 \%$ & 247 \\
\hline Ride-hail & $40 \%$ & $31 \%$ & $16 \%$ & $49 \%$ & $47 \%$ & n/a & n/a & $21 \%$ & 141 \\
\hline Taxi & $16 \%$ & $13 \%$ & $26 \%$ & $46 \%$ & $35 \%$ & n/a & n/a & $22 \%$ & 85 \\
\hline BIKETOWN & $28 \%$ & $17 \%$ & n/a & $14 \%$ & $45 \%$ & $66 \%$ & $45 \%$ & $24 \%$ & 29 \\
\hline E-scooter & $23 \%$ & $14 \%$ & n/a & $40 \%$ & $43 \%$ & $66 \%$ & $23 \%$ & $23 \%$ & 35
\end{tabular}

Percentages show the percentage of respondents using a service who used it for each trip purpose 


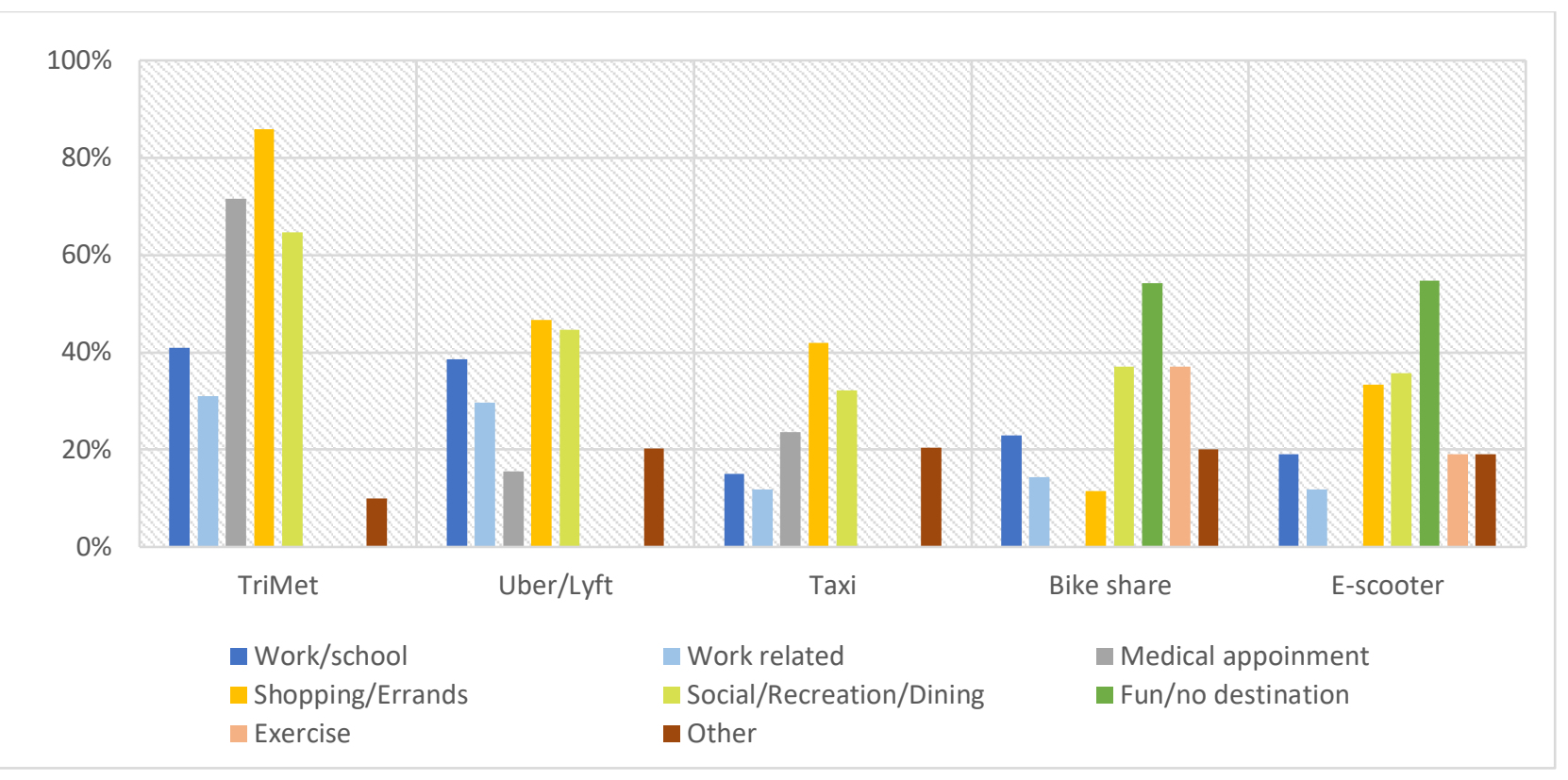

Figure 5 - Trip purpose for each mode that respondents used with the TWRAH program

\subsection{THE EFFECT OF MODE CHOICE AND ACTIVITY ACCESS WITH THE TRANSPORTATION WALLET}

Comparing the mode usage reported in the pre-survey and post-survey, we found that $99 \%$ of respondents used TriMet before TWRAH (including 7\% who had used TriMet less than once per week), while $89 \%$ of post-survey respondents used TriMet with the TW. Meanwhile, $43 \%$ of respondents used Uber or Lyft before the program ( $22 \%$ had used them less than once per week), whereas $51 \%$ of respondents engaged in this service with the TW; $35 \%$ of respondents who used taxi services before $(23 \%$ had used a taxi less than once per week), and $31 \%$ used a taxi service with the TW; $20 \%$ of respondents used bike share before the program (13\% had used it less than once per week), while $10 \%$ of them used bike share with the TW; $18 \%$ of respondents used an escooter before the program ( $11 \%$ had used it less than once per week), whereas $13 \%$ of them used an e-scooter with the TW.

We would need more information to explain the differences in percentages between pre-survey and post-survey. However, it is important to keep in mind that the before time period was at any point in prior years, whereas the post-period was only about six months. The weather might have been a factor in riding a bike or an e-scooter (that was mentioned in the barriers of using these modes by some respondents) due to the rain and season/winter between September (when the program launched) and mid-March (the start of the COVID-19 lockdown). In this section, we take a further look into some perception questions in the survey about whether the program helped participants use different transportation services and access their daily activities. Also, we present 
information about how the financial value of this program is relevant to respondents' mode choice.

\subsubsection{Did the Program Increase Usage of New Mobility Services?}

The survey asked participants whether they agreed that they tried using new modes (like bike share, e-scooters, etc.) with TWRAH, of which $48 \%$ of respondents agreed. Figure 6 and Figure 7 present the percentages of mode sign-up and usage across different perceptions. Overall, the percentages of signing up and using these modes from those who agreed (that TW program helped them try using new modes) were higher than respondents who disagreed. The result suggests that half of participants had more opportunities and options to use the mode(s) that they may have not used before. Among those respondents who agreed that they tried using new modes, $75 \%$ signed up for Uber and/or Lyft, while $70 \%$ actually used Uber or Lyft with the TW. Although $48 \%$ signed up for bike share, only $24 \%$ actually used bike share with the TW. Also, $50 \%$ signed up with an e-scooter service, but only $32 \%$ used the service. Similarly, for respondents who disagreed with the statement, there was still a gap between (the percentage of) mode sign-up and mode usage. These results suggest that this program was a good opportunity to expose participants to new modes, but more strategies might be needed to engage people in actually using the modes, particularly for bike share and e-scooter services.

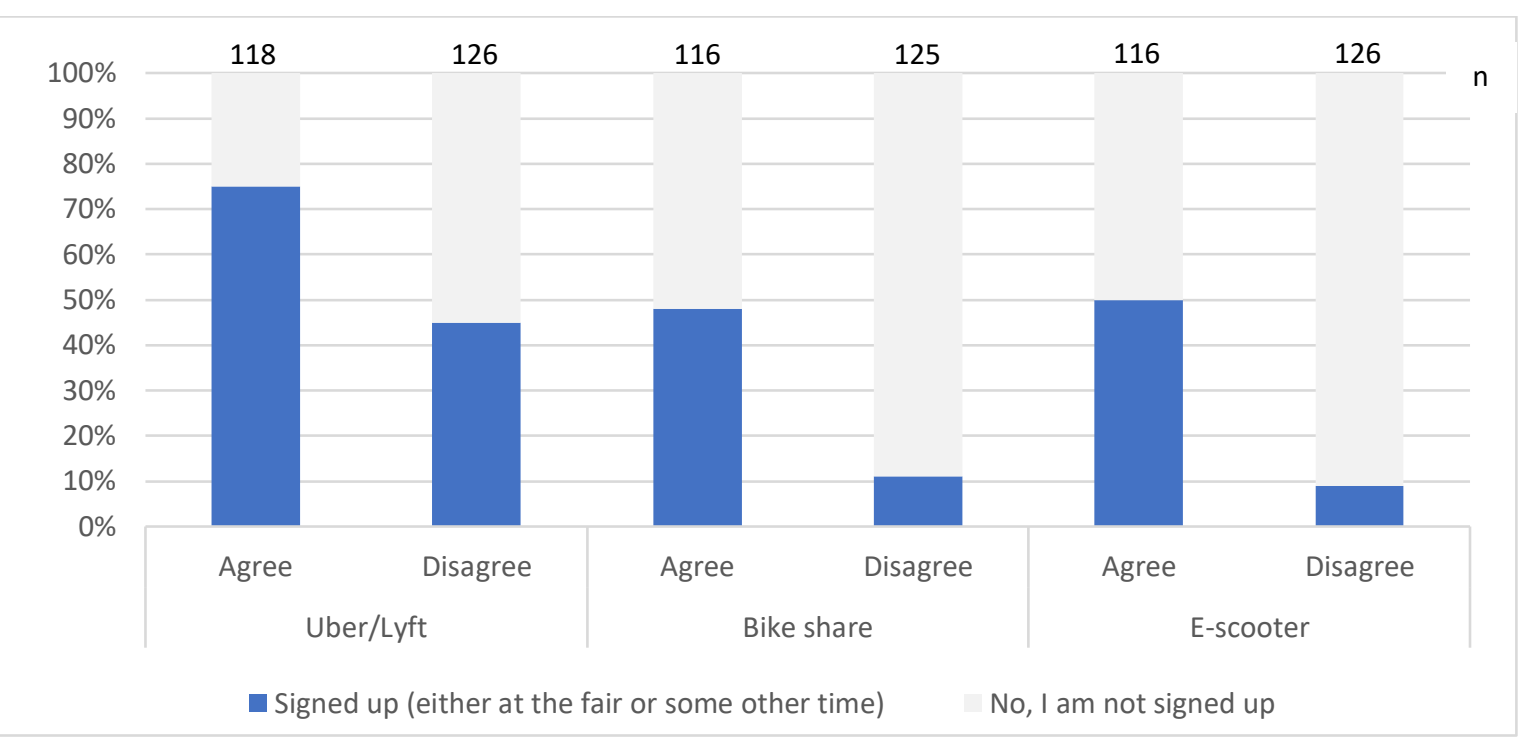

Figure 6 - Percentages of mode sign-up on the basis of the perception on whether TWRAH helped them use new mode(s) 


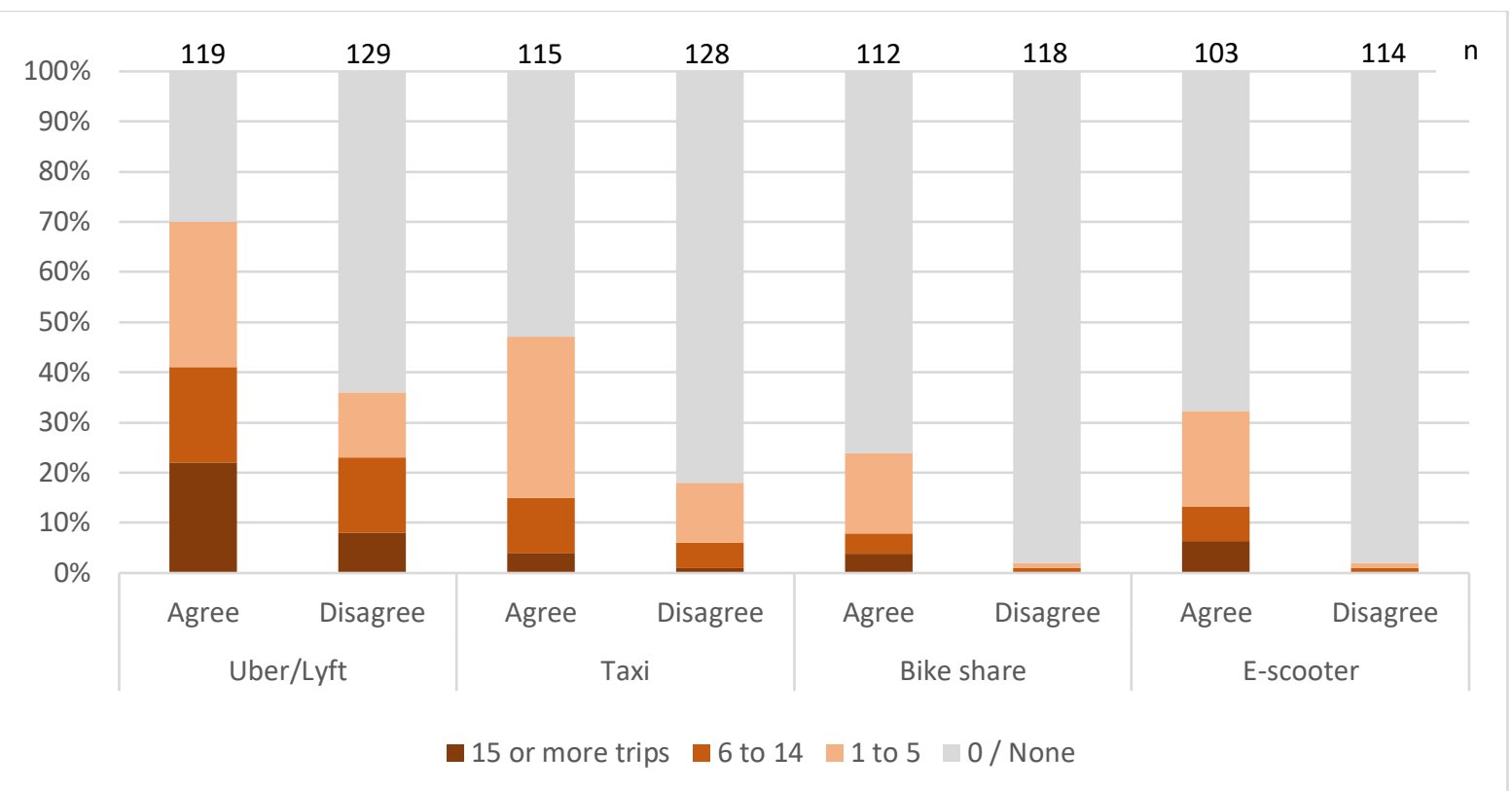

Figure 7 - Percentages of mode usage (number of trips) on the basis of the perception of whether TWRAH helped them use new mode(s)

A question on the post-survey asked participants whether they felt they were using each mode more than before TWRAH. For each mode, over half of respondents indicated that they did increase the frequency of using that mode. This suggests that the program encouraged respondents to participate in these modes more and enabled them to take more trips with these modes. Of those who used each mode, $89 \%$ and $85 \%$ of respondents indicated that they used TriMet (248 total responses) and Uber/Lyft (149 responses) more because of the TW, compared to $75 \%$ for taxi (102 responses), $62 \%$ for bike share (40 responses), and 66\% for e-scooter (50 responses).

In order to understand mode substitution behavior of participants, they were asked what modes they would have used more if they had not had the TW. Over three in five (62\%) indicated that they would walk more without the TW, while $48 \%$ reported they would use TriMet more and $26 \%$ would drive more. Also, $16 \%$ indicated they would take Uber or Lyft more, $14 \%$ would bike more, and $11 \%$ would take taxis more. Some respondents (15 responses) also reported that they would ask friends or family members for a ride, or just reduce the number of trips they took without the TW (five responses).

\subsubsection{Did the Program Increase Access for Participants?}

For each mode, we asked participants whether they were able to get to places with TWRAH that they otherwise could not. The majority of respondents perceived that these modes help them get to more places than they otherwise would without the TW. TriMet and Uber/Lyft were more likely to help their users get to places they otherwise could not reach. About $60 \%$ of respondents using TriMet, Uber/Lyft and taxi indicated that this was "always true," compared to $37 \%$ for bike share and $36 \%$ for e-scooter users. Also, $34 \%$ of TriMet users and $29 \%$ of Uber/Lyft users selected "sometimes true," compared 
to $20 \%$ for taxi, $27 \%$ for bike share and $24 \%$ for e-scooter users. Only $4 \%$ of TriMet users and $12 \%$ of Uber/Lyft users chose "always false" for this statement, compared to $36 \%$ for bike share users and $40 \%$ for e-scooter users.

Some perception questions also confirmed that the program helped respondents access activities and improved the flexibility to get around (see Figure 8 ). This program was important for respondents to get to appointments, such as doctor visits $(89 \%$ agreement). Further, $86 \%$ of participants agreed that with the program "they were able to get to places they did not have any way to get there before" and $87 \%$ agreed that "they took more trips in general" due to the TW.

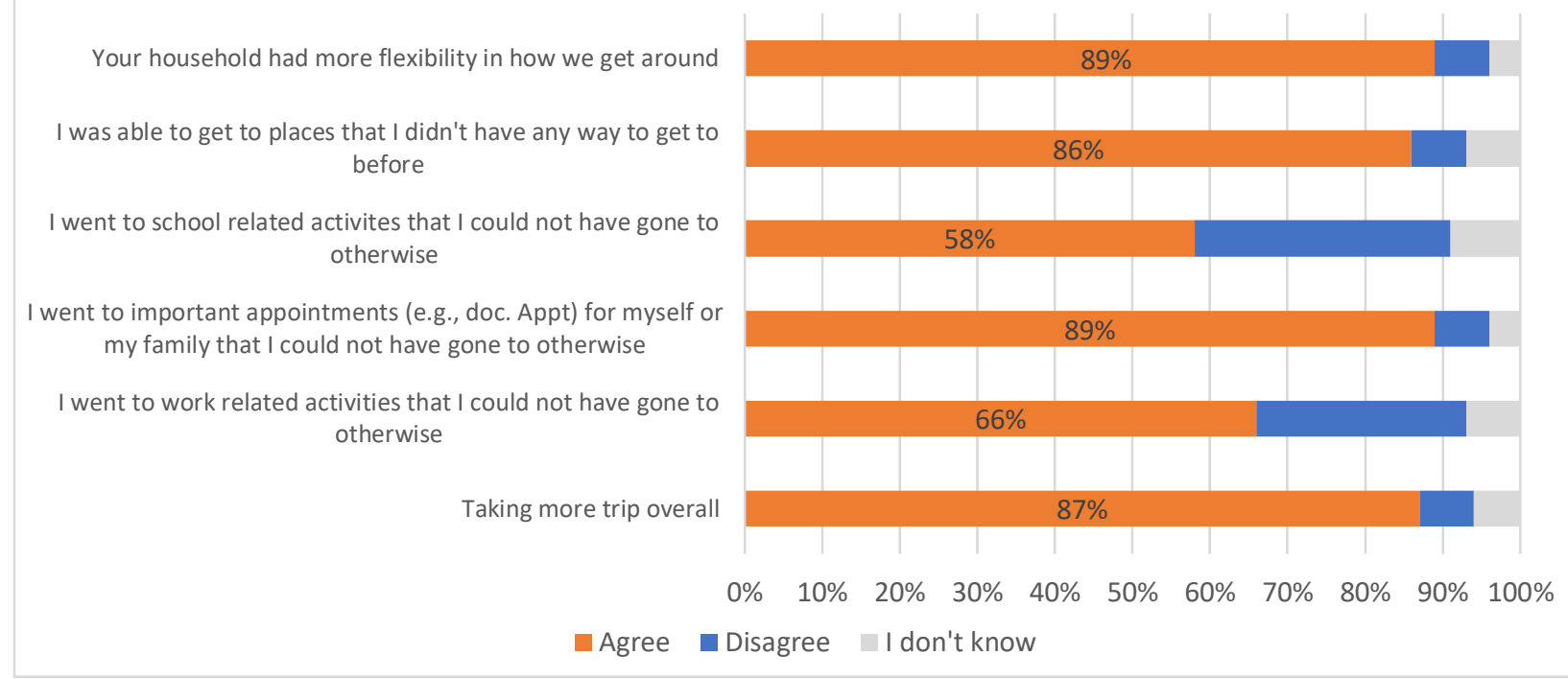

Figure 8 - The perception of whether TWRAH program helped participants with flexibility and opportunity to get to activities

\subsubsection{Will People Continue to Use the Services?}

Nearly all participants $(97 \%)$ indicated that they saved money on normal transportation costs with TW, and $95 \%$ agreed that managing their monthly budget was less stressful because of the TW. We asked participants if they would still use each mode (that they used with the TW) after they had spent all the $\$ 308$ in funds on the pre-paid card (see Figure 5). We found that $56 \%$ of TriMet users, $61 \%$ of Uber/Lyft users and $49 \%$ of taxi users reported they would use the services less after spending all TW money. Further, $47 \%$ of bike share users, $57 \%$ of e-scooter users, and $44 \%$ of taxi users said they would no longer use these modes after spending all the money, higher than Uber/Lyft (28\%) and TriMet (2\%). Therefore, the results suggest that the financial support of this program encouraged usage of certain modes among participants, especially for bike share and e-scooter services. 


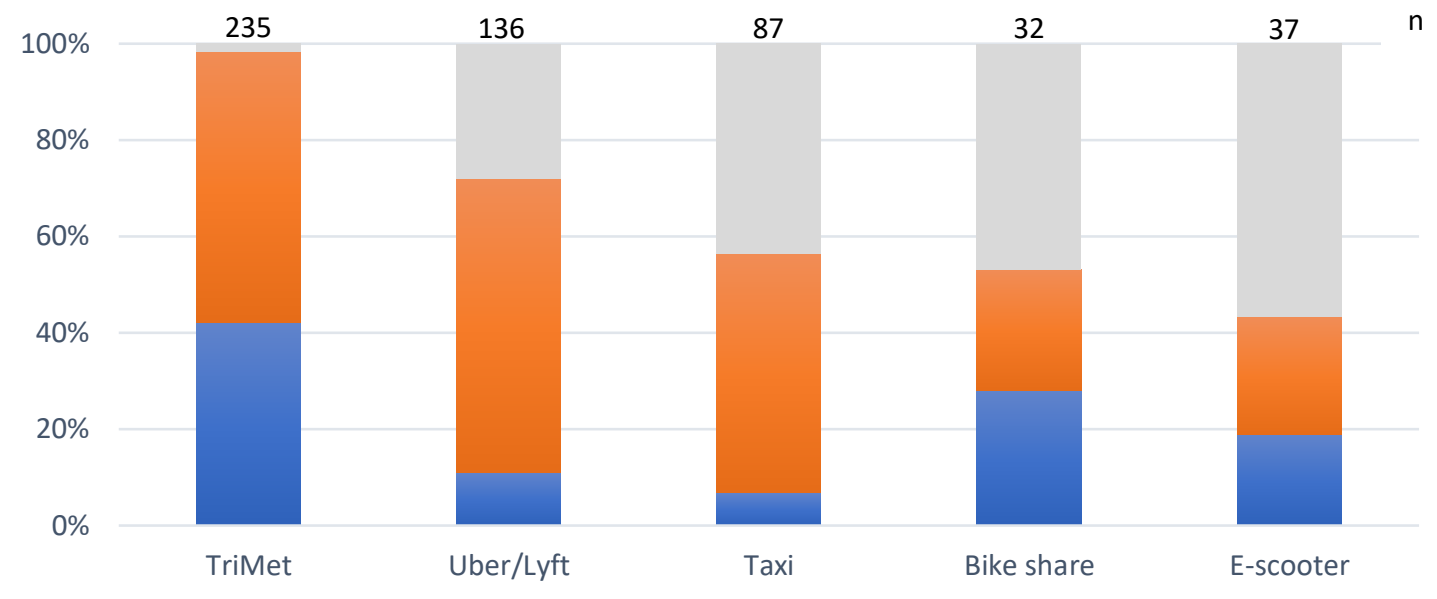

- Yes, will take about same amount $\quad$ Yes, but will take fewer $\quad$ No, no longer use it

Figure 9 - Participants' intention of using different modes after spending down TW money

\subsection{GEOGRAPHIC DIFFERENCES}

Several of the affordable housing locations were in East Portland, generally outside of the areas served by bike share, and with more limited transit, ride-hail, taxi, and escooter availability as well. Respondents from three such locations (Human Solutions, Rose CDC, and Hacienda CDC) were broken out from respondents living in buildings closer to downtown Portland. Several important differences emerged between the East Portland residents and other respondents. As shown in Table 9, East Portland residents were more likely to say they used the TW for work or school-related activities. East Portland residents were also more likely than other participants to use ride-hail, and less likely to use transit or taxi (see Figure 10).

Table 9: TWRAH stated impact on travel behavior, by geographic area

\begin{tabular}{|l|c|c|}
\hline Because of the transportation wallet & $\begin{array}{c}\text { Not East } \\
\text { Portland }\end{array}$ & $\begin{array}{c}\text { East } \\
\text { Portland }\end{array}$ \\
\hline a. .. I am taking more trips overall & $87 \%$ & $85 \%$ \\
\hline $\begin{array}{l}\text { c. .. I went to work related activities (e.g. job interviews } \\
\text { or trainings) that I could not have gone to otherwise }\end{array}$ & $60 \%$ & $\mathbf{8 1 \%}$ \\
\hline $\begin{array}{l}\text { d. .. I went to important appointments (e.g. doctor } \\
\text { appointments) for myself or }\end{array}$ & $88 \%$ & $92 \%$ \\
\hline $\begin{array}{l}\text { e. ... I went to school-related activities that I could not } \\
\text { have gone to otherwise }\end{array}$ & $\mathbf{4 7 \%}$ & $\mathbf{8 2 \%}$ \\
\hline $\begin{array}{l}\text { f. ... I was able to get to places that I didn't have any way to } \\
\text { get to before }\end{array}$ & $85 \%$ & $89 \%$ \\
\hline $\begin{array}{l}\text { i. ... my household had more flexibility in how we get around } \\
\text { (e.g. car available for use by others) }\end{array}$ & $87 \%$ & $92 \%$ \\
\hline
\end{tabular}

Percentages show agreement with each statement 


\section{RIDEHAIL TRIPS}

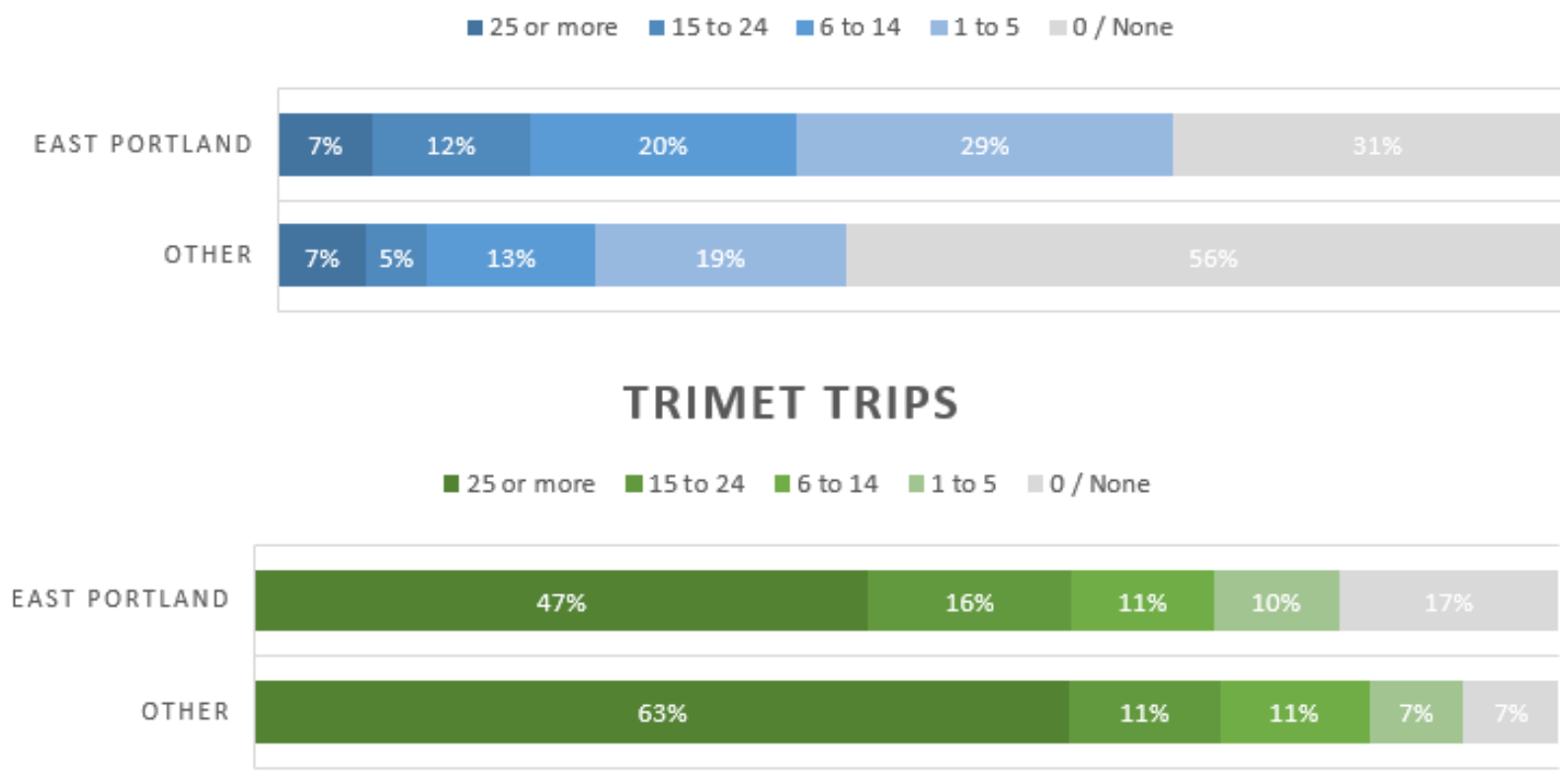

TAXI TRIPS

घ 25 or more $\square 15$ to $24 \quad 6$ to $14 \quad 1$ to $5 \quad 0 /$ None

EAST PORTLAND

OTHER

$3 \% 2 \% \quad 10 \%$

$23 \%$

Figure 10 - Mode usage by East Portland vs other participants

\subsection{TRANSPORTATION FAIR AND PROGRAM IMPLEMENTATION}

This section focuses on the effect of the Transportation Fairs (TFs), where participants could learn about services and talk to service providers, on mode sign-up and usage. We also discuss some limitations relevant to the implementation of the program that transportation agencies may consider for improvement.

In sum, $220(79 \%)$ out of 278 respondents reported they attended one of the seven TFs held by PBOT at the beginning of the TWRAH. Residents who did not attend a TF were able to get on a waiting list, through which the remaining TWs were distributed. Figure 11 and Figure 12 show that the percentage of respondents signing up for and using each service among those who went to a TF was generally higher than among those who did not attend the fair. The results suggest that the participants benefited from attending the fair where they could learn about how to sign up and use different modes. The differences in service usage between fair attendees and waitlist participants were 
not significant for TriMet (90\% of fair attendees used TriMet with the TW, compared to $88 \%$ of waitlist participants), taxi trips (29\% to $40 \%$ ) and e-scooters (17\% to $7 \%$ ).

However, fair attendees with significantly more likely to use Uber or Lyft $(55 \%$ to $35 \%$, significant at $p<.01$, Pearson Chi-Square with $z$-test) and bike share $(15 \%$ to $0 \%$, significant at $p<.01$, Pearson Chi-Square with $z$-test). Notably, respondents who did not go to the fair did not use bike share at all, even though $17 \%$ of them had signed up for BIKETOWN. Usage of e-scooters among those who did not attend the fair was also very minimal. One possibility for the lower usage of these modes could be that participants were not familiar with how to use these modes, and they would have needed more information about it if they did not attend the TF. Others may not have known that the TW could be used for these transportation services (based on some comments in the survey) without going to the fair. The results suggest an effect of the fair outreach on promoting the usage of different modes, in particular for new mobility, which is consistent with the previous outreach experience in other cities (Transform, 2018). Self-selection of attending the fairs for those who had already had a higher intention to sign up or use those services could be possible.

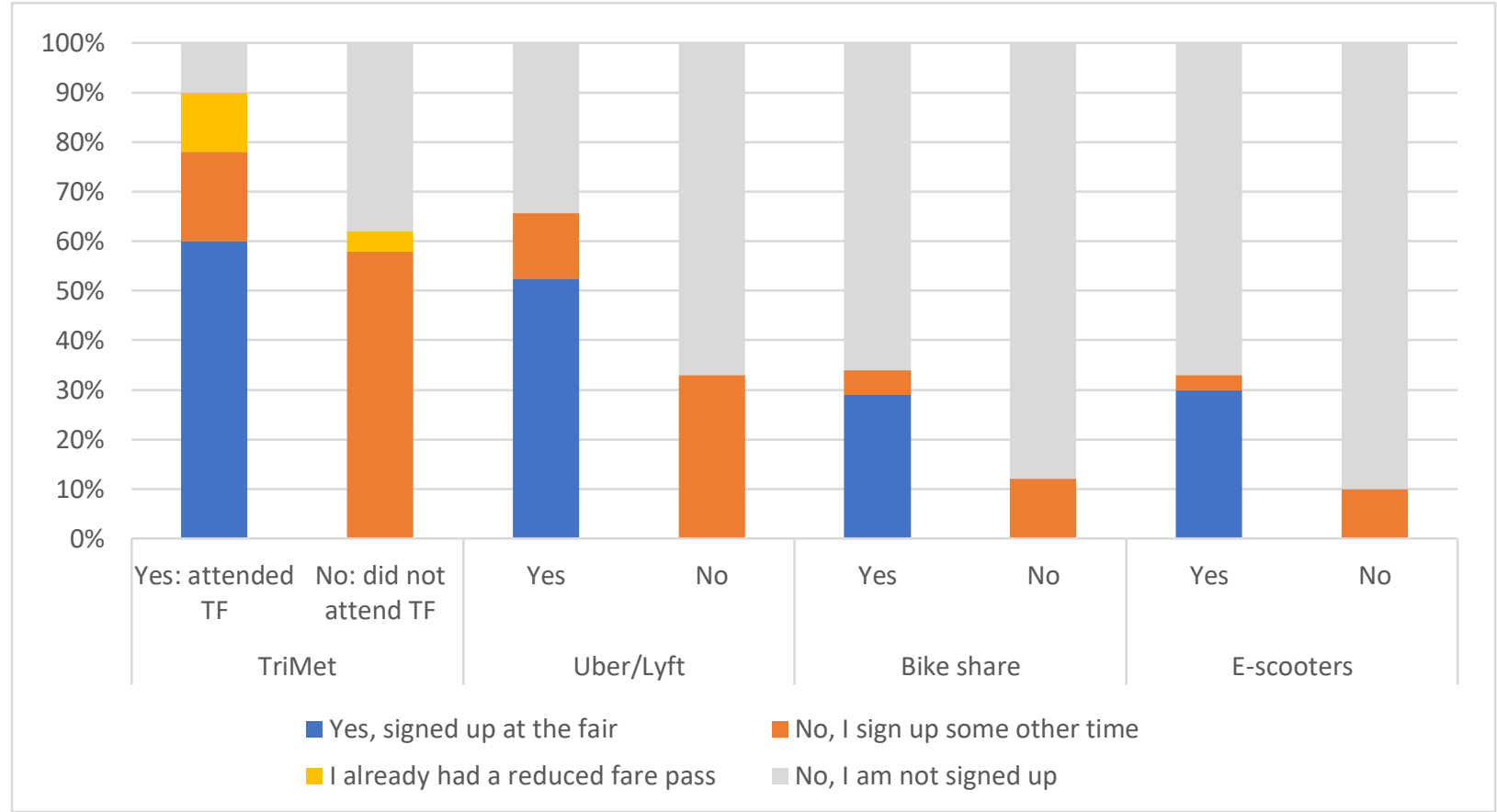

Figure 11 - Percentages of participant sign-ups by mode and their attendance of Transportation Fair 


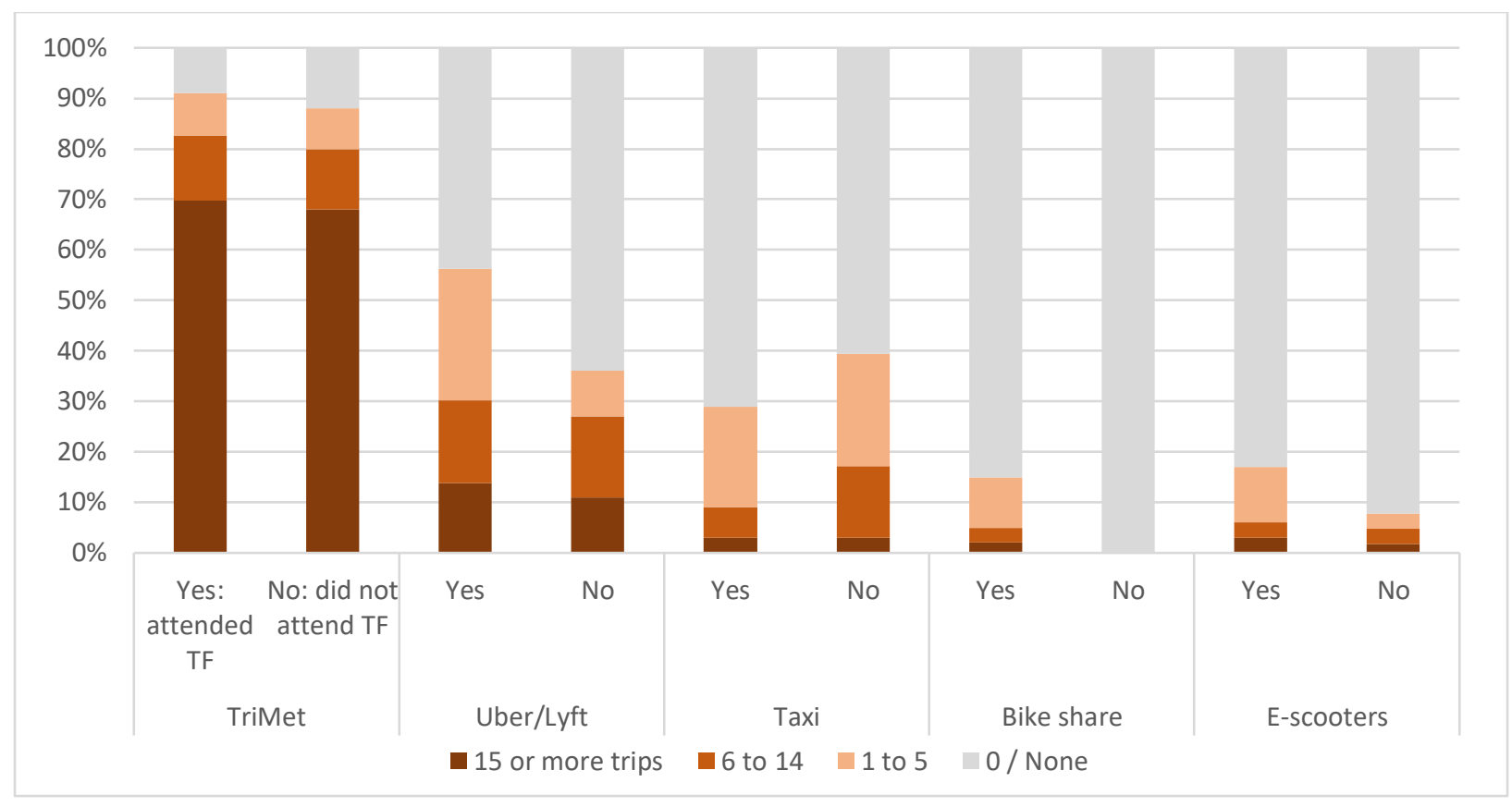

Figure 12 - Percentages of mode used by participants (number of trips) and their attendance of Transportation Fair

In the survey, respondents were also asked how useful certain aspects of the Transportation Fair were (Figure 13). Nearly nine in 10 (89\%) of respondents thought that attending the fair was very useful overall, and $84 \%$ indicated that signing up for the TriMet reduced fare pass was very useful. In addition, $94 \%$ thought it was very useful to have the fair located near their home, usually in their building lobby. Another question in the survey assessed respondents' opinions on the ease level of the program. Generally, the majority of participants rated the program as easy in terms of understanding its purpose $(78 \%)$, signing up for transportation services (78\%) and using the US Bank Visa card (80\%).

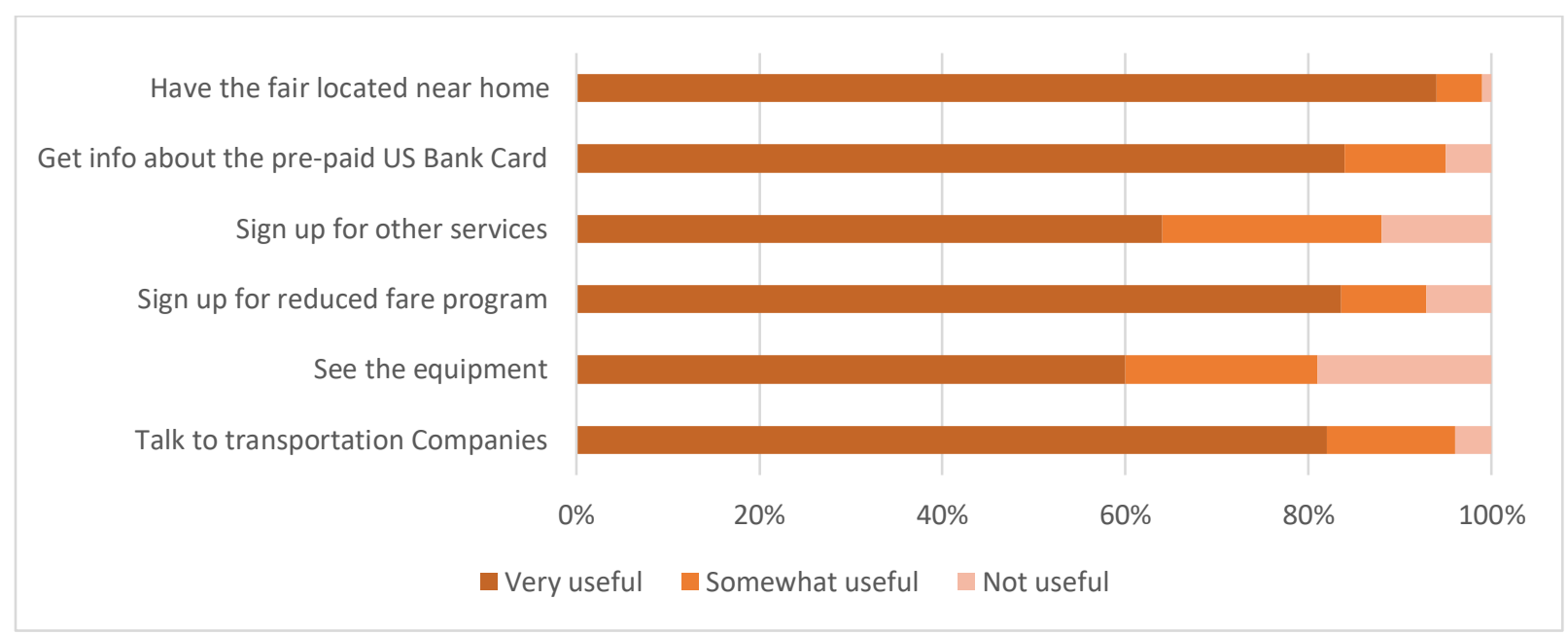

Figure 13 - Perception on the usefulness of Transportation Fairs 


\subsection{OPEN-ENDED RESPONSES}

The final survey also asked participants several open-ended questions, including "What was the best thing about the Transportation Wallet?" and "What would you change about the Transportation Wallet?" The project team reviewed and coded responses based on common themes. Responses could be coded into more than one theme, depending on what the participant wrote.

The following are the key aspects related to the benefits of using the TW among respondents:

1) Payment flexibility. Participants praised the convenient method of payment-a pre-paid Visa card. Here are some example quotes on this point: "No need to worry of buying time on the HOP card (with the TW)"; "No need to count change at fare machine"; "Being able to use the Visa card for multiple transportation options was VERY beneficial"; "The ease of using and variety of things (besides transportation) to spend it on."

2) Schedule/time savings. Some respondents also pointed out that the program helped them save time or use time more efficiently so that they could engage in more activities. For example, "I am able to schedule activities with the TW"; "I am able to go to more places and manage the time better"; "Do not need to rely on other people's schedule."

3) Sense of safety or reliability. Some respondents indicated that the program helped them choose a means of getting around that was safe and reliable. Here are some quotes: "I am able to come back home from school on late nights"; "I was able to safely transport my daughter to school and get groceries"; "It gave me confidence when travelling that I'd always be able to get there and back"; "Feeling safe to have money for a transportation emergency"; "Knowing I have reliable ride."

4) Well-being. Some respondents felt, in general, the flexibility of the program helped them be more independent. For example, "Feel freedom to go anywhere"; "able to not rely on others to get around as much."

The frequency of coded themes is shown in

Table 10 and Table 11, followed by a curated selection of example responses.

\subsubsection{Best Things About the Transportation Wallet}

Out of the 278 people who took the final survey, 274 provided a response to the question "What was the best thing about the Transportation Wallet?" In terms of the best things participants noted about the TW, appreciation for the economic impact of the wallet and appreciation for the improved mobility and independence afforded by the wallet were the top two themes, with around $32 \%$ and $30 \%$ citing each (see 
Table 10).

Table 10: What was the best thing about the Transportation Wallet Topic

Percentage of responses touching on topic

\begin{tabular}{lc}
\hline Money related (one of three themes below) & $32 \%$ \\
\hline \multicolumn{1}{c}{ Generally appreciated the extra money } & $11 \%$ \\
\hline \multicolumn{1}{c}{ Able to afford other needs } & $16 \%$ \\
\hline Less worry / stress & $8 \%$ \\
\hline Time savings / help with schedule & $12 \%$ \\
\hline Improved mobility / independence & $7 \%$ \\
\hline Improved safety & $30 \%$ \\
\hline Made job related trips & $2 \%$ \\
\hline Made trips for kids, family or school & $3 \%$ \\
\hline Made essential trips (groceries, medical appointments, etc.) & $6 \%$ \\
\hline Do more things / activities & $9 \%$ \\
\hline Program flexibility / choice easy & $3 \%$ \\
\hline Transportation Fair info/services & $5 \%$ \\
\hline Transport options general & $4 \%$ \\
\hline TriMet related & $13 \%$ \\
\hline Ride-hail & $8 \%$ \\
\hline BIKETOWN & $7 \%$ \\
\hline Scooters & $1 \%$ \\
\hline Taxi & $3 \%$ \\
\hline n & $2 \%$ \\
\hline
\end{tabular}

Among those noting the impact of the wallet on their personal economic situation, the following are examples (some examples are lightly edited for grammar, spelling, etc.):

- " "It saved me money that I can spend on health care."

- "When you're disabled and living off of Social Security it really helps."

- "Took a lot of stress off me financially. Didn't have to worry about getting around."

- "The financial relief of getting places."

- "Savings \& accessibility for someone on a hard budget."

- "Saved monthly money to help me to budget with a little more flexibility." 
- "Not paying out of pocket, having money to go places, less stress."

- "Less stressful when I managing my monthly budget."

Examples of those noting their improved mobility and independence include:

- "Feeling secure that I can get around, even when broke."

- "It relieved stress on how I was going to get around overall as I wouldn't have had the budget to do so."

- "It gave me confidence when travelling that I'd always be able to get there and back."

- "I was able to get to places that were no accessible by bus."

- "I can go where I want without thing where I will get the money to ride the bus or the train."

- "Coming back home from school on late nights."

- "being able to have extra money to get places and not relying on others to get around as much."

- "Able to go to various places and feel safe."

As can be seen from the examples provided, there was a considerable crossover between responses remarking on the value of the TW for improving their budgets, financial stress, and ability to get around safely and confidently.

A number of responses provided more specifics about the types of trips they made using the TW, including for job-related trips (3\%), family- and school-related trips (6\%), and other essential travel, such as to get groceries and for medical appointments (9\%). Examples of these types of responses include:

- "When I lost my car, I was able to get to work and keep my job by using the wallet. I also was able to safely transport my daughter to school and get groceries."

- "I only used Uber because of the wallet, I could not afford it otherwise. I used the wallet mostly to get to work."

- "Sometimes when I leave work and get to the work and the bus is right there - I get on have to search for change it's stressful. Now with the hop card I get on and it is so easy to tap and board. I'm not stressed by getting on and paying quick."

- "It got me out of emergencies. For example - my son was going to an interview for a new school and we had no way to get there. So, we took an Uber to get there using the Transportation Wallet funds. We also took my mom to a doctor's appointment when the bus was not running using the Transportation Wallet card."

- "I had the ability to take my kids to school when they were late otherwise they would have missed many days."

- "Help to get around and visit family."

- "That when I was in a bind and got too many groceries and needed to get home somehow, I could call a cab."

- "Knowing I would be able to pay for my bus pass and Lyft to doctor appointments."

- "Helping me get to Doctor appts and Grocery stores without worrying so much on cost."

Another group of respondents (about 13\%) focused on the availability of choices for transportation, or on specific services-particularly TriMet (8\%) and ride-hail (7\%). Examples of some of these responses are below: 
- "Trying new forms of transportation like scooter and bus, and passes for taxis were so useful."

- "Reduced fares and access to all transportation modes I would not have used otherwise due to cost."

- "Freedom to use transportation modes more; use Uber/Lyft more."

- "Different mode potentially can be used. Learned a lot from the program."

- "Allowing opportunity to use other modes of transportation without the added burden of at your own expense."

- "I don't have to worry about having fare for TriMet, it is on the card."

- "Being able to use for Lyft for appointments."

- "Am able to use Uber instead of the bus."

- "I really love all the options especially the BIKETOWN bikes."

- "Fun going to the booths and getting something cheaper on budget to have the whole year's TriMet instead of monthly passes. Want to use BIKETOWN to exercise. Nice to have cab fare for rainy days, emotional days, and for animal appointments."

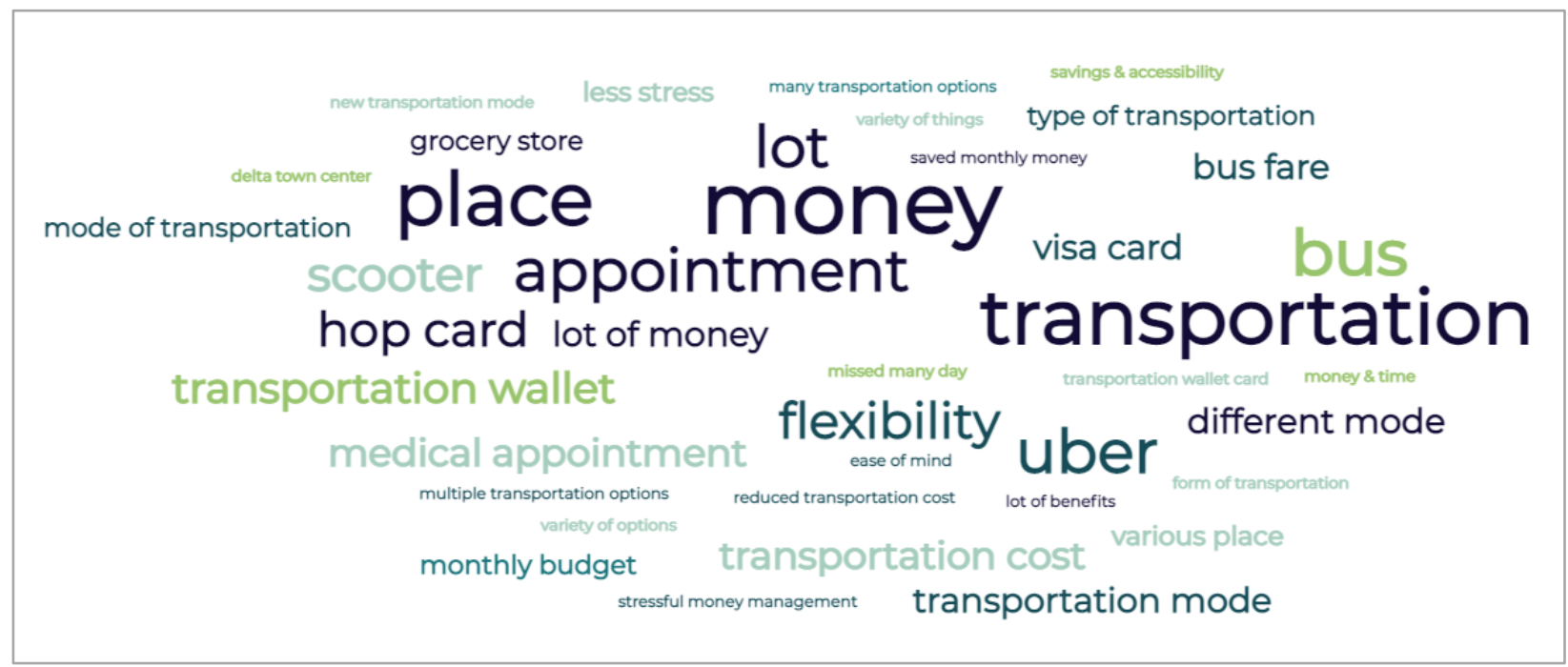

Figure 14 Word map of frequent responses to best thing about the TW

\subsubsection{What Participants Would Change with the TW Program}

In terms of responses to the question of what participants would change about the program, 266 out of 278 provided some response. Most of those responses reflected on positive experiences in the program (Table 11). For example, over half the responses indicated that they would not change anything. Another subset of responses indicated that they would include more funds in the wallets, or extend and expand the program to cover a greater length of time, more participants, more housing providers and locations, etc. 
Table 11: What would you change about the Transportation Wallet

\begin{tabular}{lc} 
Topic & $\begin{array}{c}\text { Percentage of } \\
\text { responses touching } \\
\text { on topic }\end{array}$ \\
\hline Nothing & $52 \%$ \\
\hline More Money & $8 \%$ \\
\hline Extend / make program permanent & $4 \%$ \\
\hline Offer to more people / at more locations & $3 \%$ \\
\hline $\begin{array}{l}\text { More clarity on card / program (more information on how to use the TW, } \\
\text { expiration info, technical help, etc.) }\end{array}$ & $8 \%$ \\
\hline $\begin{array}{l}\text { More help with services (didn't know how to use some services, or how to use } \\
\text { the TW with some services) }\end{array}$ & $5 \%$ \\
\hline Card problems (rejected by some providers, lacked pin, reloading) & $3 \%$ \\
\hline Use for more transport needs (e.g. gas, intercity travel, etc.) & $5 \%$ \\
\hline Issue with a service (extra charges, fees, card not accepted etc.) & $9 \%$ \\
\hline Expiration issues (not knowing or using funds by expiration) & $2 \%$ \\
\hline Better promotion of program & $1 \%$ \\
\hline TF issues (not able to attend, too crowded, etc.) & $2 \%$ \\
\hline Program abuse & $1 \%$ \\
\hline $\mathrm{n}$ & 266 \\
\hline
\end{tabular}

Among the people who offered some criticism, about $8 \%$ felt that more clarity and information about how to use the pre-paid Visa card and program would be helpful, and another $5 \%$ felt more help using the services would be helpful. Some examples of comments received in this vein include:

- "Be more specific on what the money can and can't be used in"

- "I don't know how to check balance. Some way to do that through a website or app would be great"

- "I did have a little speed bump getting started because the instructions to get set up were a tiny bit vague. Not so much so that I couldn't figure it out but if I were a senior I would want some extra help with the tech stuff."

- "I would make the process more user-friendly."

- "More information on how to use it for the first time, it was a bit difficult even for someone who is tech wise." 
- "More Transportation FAIRS. Or even Ideas for taking mini day trips or adventures"

- "More info about now mode like e-scooter"

- "More information about Uber/Lyft. Did not know that everything was free. Was too embarrassed to approach PDX WAV or know to for Uber/Lyft."

- "Let the info about the program out there more to more ppl, e.g., bus driver, so that the participants can get help."

- "Providing more info about other services (more clearly)"

Some participants noted challenges they encountered with specific services. For example:

- "It seems like it could not be used to tip Lyft drivers. They are supposed to be tipped on your card, not cash. I want to always tip. So, this was a problem and some transactions had issues."

- "It was difficult to use with taxi because it didn't have a CHIP"

- "It would not connect to Lyft"

- "Make it easier to put \$ on TriMet"

- "Since it was prepaid, I wasn't able to use it for BIKETOWN"

\subsection{TRANSPORTATION WALLET CARD BALANCES}

In late 2020, or just over a year from when most participants received their TWs, PBOT checked the balance on pre-paid Visa cards that were issued to participants. Our assessment of the final balances found that, on average, there was $\$ 59$ remaining. Just over two-thirds of all participants had less than $\$ 50$ left on their cards, while $12 \%$ had between $\$ 100$ and $\$ 199$ and $12 \%$ had over $\$ 200$ remaining. Average and median final balances are shown in Table 12 by housing partner, TriMet pass selection, final survey participation, Transportation Fair attendance, and home language. It is likely that, absent COVID-19-related disruptions, more participants would have used a greater proportion of the TW funds. However, it should also be noted that the small number of participants with large balances likely skew the mean balances shown in Table 12 (notably in cases where the median and mean differ significantly).

As expected, participants who selected the annual pass, which exhausted their initial TW funds, had virtually no remaining balance (the small $\$ 2$ remaining balance is likely due to survey participants having the option of receiving a $\$ 40$ credit added to their card).

Final survey participants had slightly lower remaining balances than those who did not take the final survey - a difference which likely would have been somewhat greater before taking into account that some participants opted to receive the $\$ 40$ bonus credit for taking the survey. This suggests that survey participants might have been somewhat more engaged in the TWRAH program than those who did not take the survey. Program participants who did not take the final survey also show a major difference between mean balance $(\$ 63)$ and median balance $(\$ 0)$, suggesting that a minority likely had very large remaining balances. 
We did not see a significant difference between those who attended a Transportation Fair compared to those who signed up off a waitlist. Finally, we did see that participants who told us they only spoke English at home had lower remaining balances ( $\$ 51$ compared to $\$ 67$ to $\$ 71$ for others), suggesting that language barriers may have been an impediment to maximizing program participation.

Table 12: Mean final TW pre-paid Visa balances

\begin{tabular}{|c|c|c|}
\hline & Mean balance & Median balance \\
\hline Total & $\$ 59$ & $\$ 4$ \\
\hline \multicolumn{3}{|l|}{ Housing partner } \\
\hline Catholic Charities & 42 & 14 \\
\hline Home Forward & 54 & 2 \\
\hline PCRI Inc. & 42 & 0 \\
\hline REACH CDC & 82 & 41 \\
\hline Hacienda CDC & 72 & 27 \\
\hline Human Solutions & 56 & 15 \\
\hline Rose CDC & 20 & 1 \\
\hline \multicolumn{3}{|l|}{ TriMet Pass Selection } \\
\hline Annual Pass & 2 & 0 \\
\hline Monthly Pass & 91 & 56 \\
\hline Reduced, not unlimited & 71 & 40 \\
\hline No Reduced Fare & 49 & 18 \\
\hline \multicolumn{3}{|l|}{ Final Survey participation } \\
\hline Took Final Survey & 56 & 14 \\
\hline Did not & 63 & 0 \\
\hline \multicolumn{3}{|l|}{ Transportation Fair Attendance } \\
\hline Attended TF & 57 & 11 \\
\hline Waitlist & 54 & 25 \\
\hline \multicolumn{3}{|l|}{ Home language } \\
\hline Only speak English at home & 51 & 7 \\
\hline Speak other languages at home & 71 & 40 \\
\hline Speak both English and other languages at home & 67 & 34 \\
\hline
\end{tabular}

Shaded rows in Housing partner section are primarily East Portland locations

To get more specifics about how program delivery might be improved, we looked at the open-ended question on what participants would change about the program. The following aspects were highlighted as important for program implementation.

1) Education on the program and how to use different modes. While the majority of respondents agreed on the ease of the program and the usefulness of the fairs, 
some suggested that the program should distribute more understandable and straightforward information to participants, particularly more information about how to sign up and use the new mobility options (including Uber and Lyft). One participant pointed out that "it was a bit difficult even for someone who is techwise." Another respondent suggested that a day trip/tour of learning how to use different modes would be more straightforward and helpful. The agency may also need to consider further outreach to participants who did not attend the fair given that the fair was helpful to sign up and use all services.

2) Coordination with different services. Some respondents noted that they had problems with the pre-paid card not being accepted by some service providers, which resulted in not being able to use the TW on those services (especially for cab services and Uber or Lyft). Here are some examples, "Taxi services didn't go through the card"; "Better management on other services like Uber \& Lyft and make them more prepared"; "Tell companies what the program it is. People providing service don't know or don't accept the service." In addition, some respondents also suggested more methods of reloading money on a TriMet pass or getting a new pass (e.g., monthly pass), such as "allowing Hop pass be loaded at different locations/stores" (instead of going to the TriMet office downtown).

3) Other potential services. Some respondents suggested that the program could expand to other services with the TW, such as intercity bus service, car rental (along with the fact that the carsharing service Car2Go left Portland shortly after the program began), and other services for low-income people/communities in need. 


\subsection{FINDINGS FROM PROVIDER INTERVIEWS AND DEBRIEF}

In addition to the surveys of TWRAH participants, the project team interviewed key contacts at the seven housing providers (usually the resident coordinator), and hosted a post-Transportation Fair debrief with representatives from PBOT, housing providers, and transportation services. The following are key lessons noted from these interviews.

\subsection{VALUE OF HAVING FAIRS LOCATED AT RESIDENCE LOCATIONS}

Resident coordinators noted that they felt there was incredible value to participants in having the program run through a trusted partner (e.g., the housing provider/coordinator) and being held at an easy location near or (in many cases) at their home building. These factors encouraged many people to participate, including allowing those with various mobility challenges (including physical mobility challenges as well as those lacking the time or money to travel to an offsite location) to participate in a program that could help improve their mobility situation.

\subsection{FREEDOM TO CHOOSE HOW TO SPEND TRANSPORTATION FUNDS}

Debrief participants noted that the TW provided a sense of "freedom" to participants by allowing them to choose which transportation services to spend their \$308 pre-paid Visa card on, rather than prescribing how they should spend the funds.

\subsection{CHALLENGE OF PROVIDING INTERPRETATION AND TRANSLATION SERVICES}

The provision of interpreters/translators was done in a mostly ad hoc manner, with translations for non-English speaking participants (for initial sign-up, surveys, etc.) done by family members or neighbors. Phone interpretation was used in some cases, but was time-consuming and cumbersome. Appointment times were suggested as one potential solution to the problem of people waiting a long time to meet with an interpreter.

\subsection{CHALLENGES USING PRE-PAID CARDS}

Resident coordinators noted that residents were confused about how to use the prepaid card, including checking how much money was left on the card. They also noted that residents were having some trouble getting service providers to accept a pre-paid, rather than credit, card for some purposes - particularly in situations where credit holds were needed to use a service. (Note: Over the course of the program, some service providers changed policies to accept pre-paid cards). 


\subsection{PROGRAM AS DISCOUNT PROGRAM ENROLLMENT MECHANISM}

The value of partnering with TriMet on enrollment in the low-income fare program was considerable. Even without funds to use on the service, the discount program would provide participants with half-price transit fares. Streamlining that enrollment process, and completing enrollment at the fair was highly valued.

\subsection{ACKNOWLEDGEMENT OF RESIDENT COORDINATOR ROLE}

Between assisting with organizing and participating in Transportation Fairs, and serving as a program point of contact for residents after the fairs, resident coordinators do a lot of work related to outreach, enrollment, and personalized assistance for participants. The program recognized this by providing them with TW as well, which also helped them know how to use it and provide more informed assistance to residents. 


\subsection{OPPORTUNITIES FOR IMPROVEMENT}

A few suggestions for improving the TWRAH program, based on input from participants and providers, are discussed in this section. Note that COVID-19-related precautions and restrictions, occurring about six months into the program, provided challenges, particularly around in-person engagement and promotion activities.

\subsection{TWRAH PARTICIPANTS WOULD BENEFIT FOR MORE ONGOING ASSISTANCE}

Participants encountered a number of problems that could be addressed through some enhanced level of ongoing assistance. These include help with activating TW cards (if not done on-site), transferring funds into service accounts, and navigating challenges presented by the fact that the pre-paid card was sometimes not an acceptable form of payment (e.g., when credit cards were needed for charge holds).

Further assistance could also help to address the gap between the number of people who sign up for various services and those who actually use those services. Particularly, there could be more specific outreach around the use of BIKETOWN throughout the TW program.

One possible means of easing the burden and technical challenges associated with the pre-paid card would be including an app-based TW option and/or directly funding service provider accounts based on participants' choices.

\subsection{MORE OPPORTUNITIES TO MEET SERVICES PROVIDERS}

Participants could benefit from increased opportunities to actually test out services (e.g., use apps, ride scooters/bikes, etc.). Some participants may need lessons in using scooters, bikes, ride-hail, as well as transit information.

\subsection{ACTIVATED CARDS AT FAIRS}

To the extent possible, participants should leave the TFs ready to walk out the door and start using the TW. Having activated cards to distribute at the fair (or providing credit to participants in an app interface) could help in encourage program participation generally, and help in further promoting some of the services that participants may not have previously tried, as they would have potentially just heard about e-scooters, BIKETOWN or ride-hail, and might be curious to try.

\subsection{EXPLORE WAYS TO HELP PARTICIPANTS BETTER UNDERSTAND TRIMET FARE-CAPPING}

Since TriMet pass holders can build toward a day or month pass with single fares, it may be more economical to pay per ride and earn passes when they ride frequently. 
While some people may prefer the simplicity of spending their full wallet on the annual pass selection, others may benefit from making better use of the fare-capping structure. By not spending their entire TW up front on a TriMet annual pass, they might be more inclined to try other transportation options, and learn about services they might not have otherwise used or have funds available to take a taxi or ride-hail when an emergency trip need presents itself. Further, since transportation needs may change over time, the annual pass could lock people into a pass that they might not use to the fullest down the road. Of course, the COVID-19 pandemic could not be anticipated, but in this case it left most participants who chose the annual pass with a transportation pass they would use on a very limited basis for many months.

\subsection{EXPLORE WAYS TO ENSURE PARTICIPANTS SPEND DOWN THEIR PRE-PAID CARDS}

PBOT's efforts to notify participants of remaining balances (particularly for cards without any use), provision of deadlines for first-card use, and eventual de-activation of some unused cards (which may have been lost) were helpful attempts to maximize the impact of the TW program. However, there were still many participants with significant balances on their cards even a year after they received them. Increased engagement with participants around how they could spend the TW value, perhaps in combination with ongoing assistance and trip planning, could help further improve card use. 


\subsection{CONCLUSION}

This study evaluated how a transportation assistance program from PBOT could help low-income residents to improve their travel options in Portland, particularly using different modes.

\section{How did participants use the TW (e.g., mode usage, trip purpose)?}

Overall, the percentages of respondents who signed up for a TriMet reduced fare pass (74\%) and Uber or Lyft service (59\%) (either signed up at the fair or some other time) were higher than the percentages of those who signed up for bike share $(29 \%)$ and escooter share (28\%) services. In regard to the mode usage, $90 \%$ of respondents used the TW on TriMet services. Over half of respondents (52\%) used Uber or Lyft and 31\% of them used taxi services, compared to $12 \%$ for bike share and $15 \%$ for e-scooters. With the TW, the participants appeared to use each mode more than they would have otherwise. Shopping (e.g., grocery shopping) and errand trips were the most frequent trip type for people who used the TW for TriMet (86\%), Uber/Lyft (47\%) and taxi trips $(42 \%)$. Trimet $(71 \%)$ and taxi (24\%) played an important role in helping respondents go to or from medical appointments. For social/recreation/dining trips, over $60 \%$ participants used TriMet, over $40 \%$ used Uber and Lyft, and around $30 \%$ to $40 \%$ used taxis, bike share and e-scooters.

\section{Did the program encourage participants to try new modes to get around?}

Nearly half of the respondents indicated that they tried to use new modes that they never used before with the TW, which was correlated with increased sign-ups and usage of ride-hail, e-scooter and bike share services. Although TriMet and ride-hail sign-ups and usage was highest among the available services, it is still notable that $28 \%$ to $29 \%$ of participants signed up for e-scooter and bike share services, even if many did not proceed to use the services. This highlights the potential of such a program, but also the need for programs to engage further on how to transition people from signing up for a service to actually using that service.

\section{What were the effects of the individual support offered by the Transportation Fairs and the program implementation on participants' travel choices?}

The Transportation Fairs appeared to boost participant sign-ups and use of transportation services, particularly new mobility services. Notably, respondents who did not go to the fair did not use bike share at all, and usage of e-scooters among those who did not attend the fair was also minimal.

These findings signify some level of effectiveness of this program in providing more mobility options and enhancing accessibility for low-income residents. The flexibility and convenience of this program were also highlighted in survey comments by participants regarding the payment method and scheduling time (for activities). Participants' survey responses also indicate that the program reduced stress related to how people might meet their basic travel needs or get around in the case of unexpected or emergency travel needs, all while reducing financial stress. 
Input from participants suggests that several aspects can be improved. One would be to improve the way information about the program and new mobility usage is conveyed, specifically for those who never use phone apps to travel around. Another aspect would be to explore participants' experiences when using different services. For instance, safety concerns about bike share and e-scooter share services and age-related barriers (e.g., physical ability) were stressed by the participants in terms of the challenge of using these modes. This is consistent with previous studies about safety concerns as a barrier for using new mobility. Thus, transportation agencies may be limited in their promotion of these modes without further strategies to address perceptual and objective barriers in future programs. Other potential research for this program could be looking into the activity space (the area within which people travel or move during the course of their daily activities) of participants using different modes with TWRAH compared to the area when they did not have the TW so that we can gain more insights into the effect of the program on their travel behavior. 


\subsection{REFERENCES}

ACEEE. (2019). Low-Income Transportation Access / ACEEE. https://database.aceee.org/city/low-income-transit

Blumenberg, E., \& Agrawal, A. W. (2014). Getting Around When You're Just Getting By: Transportation Survival Strategies of the Poor. Journal of Poverty, 18(4), 355378. https://doi.org/10.1080/10875549.2014.951905

Blumenberg, E., \& Manville, M. (2004). Beyond the spatial mismatch: Welfare recipients and transportation policy. Journal of Planning Literature, 19(2), 182-205.

Boarnet, M. G., Giuliano, G., Hou, Y., \& Shin, E. J. (2017). First/last mile transit access as an equity planning issue. Transportation Research Part A: Policy and Practice, 103, 296-310.

Cass, N., Shove, E., \& Urry, J. (2005). Social Exclusion, Mobility and Access <sup/>. The Sociological Review, 53(3), 539-555. https://doi.org/10.1111/j.1467954X.2005.00565.x

City of Oakland. (2018). Shared Mobility Outreach Recap. City of Oakland. https://www.oaklandca.gov/topics/shared-mobility-programs

Clifton, K. J. (2004). Mobility strategies and food shopping for low-income families a case study. Journal of Planning Education and Research, 23(4), 402-413.

Cohen, S., \& Cabansagan, C. (2017). A Framework for Equity in New Mobility.

Corburn, J. (2009). Toward the healthy city: People, places, and the politics of urban planning. Mit Press.

DeGood, K., \& Schwartz, A. (2016). Can New Transportation Technologies Improve Equity and Access to Opportunity?

DeMeester, L. R., Mjahed, L. B., Arreza, T., \& Covill, N. (2019). Arlington County Shared Mobility Devices (SMD) Pilot Evaluation Report.

https://mobilitylab.org/research-document/arlington-county-shared-mobilitydevices-smd-pilot-evaluation-report/

Dillahunt, T. R., Kameswaran, V., Li, L., \& Rosenblat, T. (2017). Uncovering the values and constraints of real-time ridesharing for low-resource populations. Proceedings of the $2017 \mathrm{CHI}$ Conference on Human Factors in Computing Systems, 2757-2769.

Dillahunt, T. R., \& Veinot, T. C. (2018). Getting there: Barriers and facilitators to transportation access in underserved communities. ACM Transactions on Computer-Human Interaction (TOCHI), 25(5), 1-39.

Easley, J. (2018). Spatial mismatch beyond black and white: Levels and determinants of job access among Asian and Hispanic subpopulations. Urban Studies, 55(8), $1800-1820$.

Fan, Y. (2012). The planners' war against spatial mismatch: Lessons learned and ways forward. Journal of Planning Literature, 27(2), 153-169.

Fedorowicz, M., Bramhall, E., Treskon, M., \& Ezike, R. (2020). New Mobility \& Equity: Insights for Medium-Size Cities. 51.

Golub, A., Serritella, M., Satterfield, V., \& Singh, J. (2018). Community-based assessment of Smart Transportation needs in the City of Portland. 
Graham, P., \& Mulley, C. (2012). Public transport pre-pay tickets: Understanding passenger choice for different products. Transport Policy, 19(1), 69-75.

Heinen, E., \& Mattioli, G. (2019). Does a high level of multimodality mean less car use? An exploration of multimodality trends in England. Transportation, 46(4), 10931126. https://doi.org/10.1007/s11116-017-9810-2

Kain, J. F. (1968). Housing segregation, negro employment, and metropolitan decentralization. The Quarterly Journal of Economics, 82(2), 175-197.

Kodransky, M., \& Lewenstein, G. (2014). Connecting Low-Income People to Opportunity with Shared Mobility. Institute for Transportation and Development Policy and Living Cities. http://livingcities.s3.amazonaws.com/resource/284/download.pdf

Mattioli, G., \& Colleoni, M. (2016). Transport disadvantage, car dependence and urban form. In Understanding mobilities for designing contemporary cities (pp. 171190). Springer.

McNeil, N., Dill, J., MacArthur, J., Broach, J., \& Howland, S. (2017). Breaking barriers to bike share: Insights from residents of traditionally underserved neighborhoods.

Rayle, L., Dai, D., Chan, N., Cervero, R., \& Shaheen, S. (2016). Just a better taxi? A survey-based comparison of taxis, transit, and ridesourcing services in San Francisco. Transport Policy, 45, 168-178.

Sandstrom, M. (2010). Assessing the need for subsidized personal mobility options for low-income families in San Mateo County, California [PhD Thesis]. Masters Thesis. The Mineta Transport Institute. San Jose University.

Schweitzer, L., \& Valenzuela, A. (2004). Environmental injustice and transportation: The claims and the evidence. Journal of Planning Literature, 18(4), 383-398.

Shaheen, S. A., Cohen, A. P., Zohdy, I. H., \& Kock, B. (2016). Smartphone applications to influence travel choices: Practices and policies. United States. Federal Highway Administration.

Shaheen, S., \& Cohen, A. (2019). Shared Micromoblity Policy Toolkit: Docked and Dockless Bike and Scooter Sharing.

Shirgaokar, M. (2018). Expanding seniors' mobility through phone apps: Potential responses from the private and public sectors. Journal of Planning Education and Research, 0739456X18769133.

Syed, S. T., Gerber, B. S., \& Sharp, L. K. (2013). Traveling towards disease: Transportation barriers to health care access. Journal of Community Health, 38(5), 976-993.

Thistle, I., \& Paget-Seekins, L. (2017). The Youth Pass: A Study of the Conflicts Between Ideal and Practical Research Design in a Pilot Social Program. Transportation Research Record, 2652(1), 116-123.

TransForm. (2018). Bike Share for All Outreach Results. TransForm. https://www.transformca.org/landing-page/shared-mobility

TriMet. (2019). Access Transit: Low-Income Fare Programs. https://trimet.org/accesstransit/

Wardman, M., \& Hine, J. (2000). Costs of Interchange: A Review of the Literature. 


\subsection{APPENDIX: SURVEY INSTRUMENTS}

A: Pre-Survey administered by PBOT

B: Post-Survey administered by PSU 


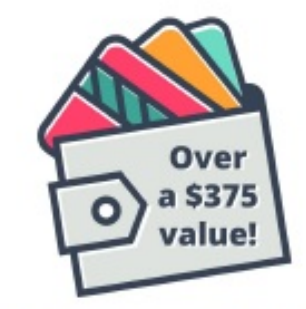

Transportation

Wallet

\section{Transportation Wallet for Residents of Affordable Housing Pilot}

Thank you for being a part of the Portland Bureau of Transportation's (PBOT)

Transportation Wallet Pilot Program for Residents of Affordable Housing.

You will be receiving a package of transportation incentives and information for you to use over the coming months. This Transportation Wallet will include offers like:

- A HOP Card to ride MAX, bus or Portland Streetcar

- A BIKETOWN for ALL membership

- Discounted e-scooter rides

- Coupons for rides with Uber, Lyft and/or Taxis

- Coupon for car2go/ SHARE NOW

Please take a few minutes to answer the survey questions on the following pages.

We will be doing a follow up survey in January 2020 after you get some time to use your package of transportation options.

Once you complete the survey, please hand it in at the table to receive your Transportation Wallet and other information.

If you need translation, please ask someone at the check-in table. 
1. Name:

2. Name of your apartment building:

3. How do you usually get to work or school? How often do you use that specified mode of transportation?

If you are retired or this is not applicable, please skip to the next question. Select only ones that apply to you.

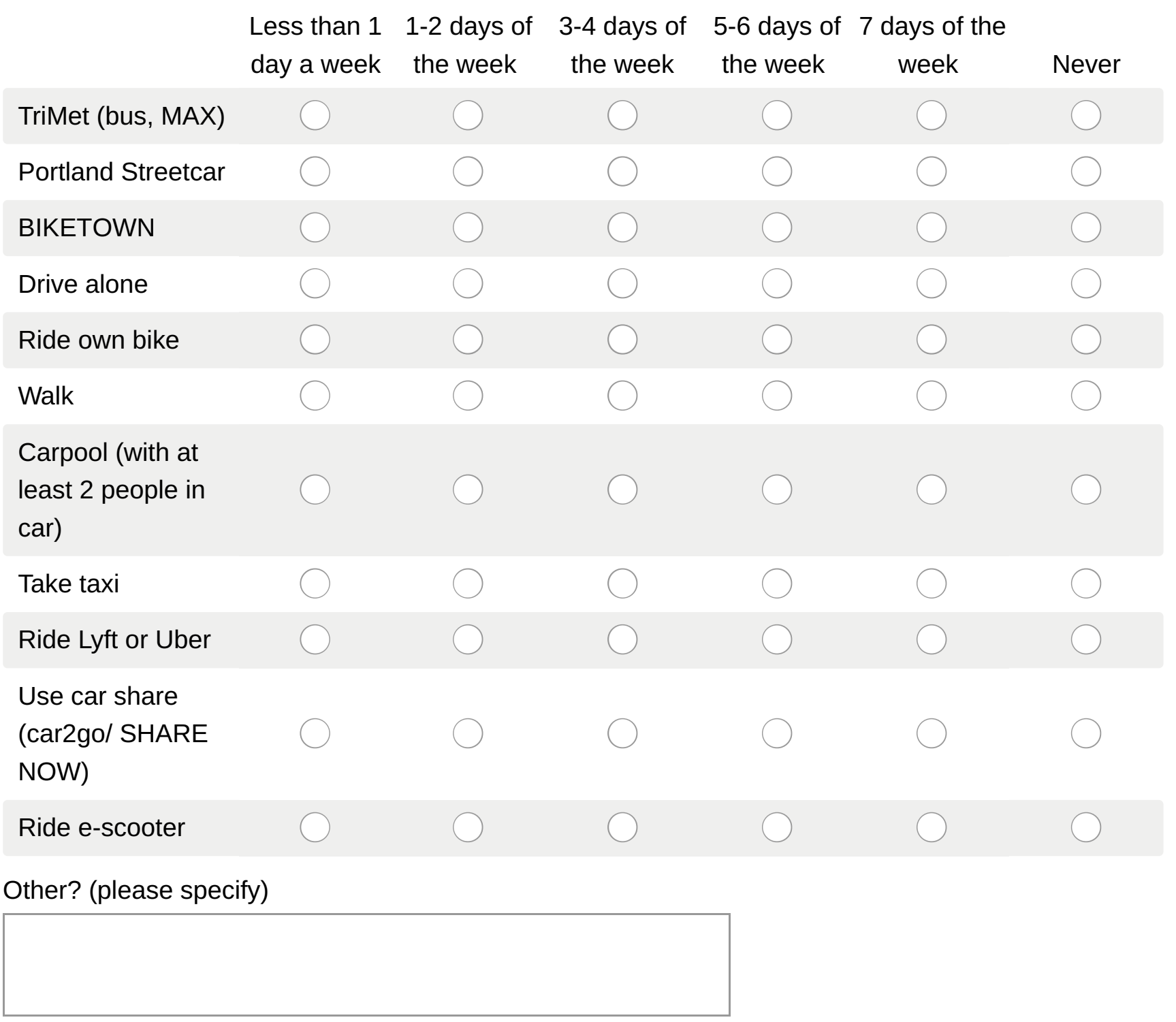


4. How do you usually get around for trips, such as shopping, errands, visiting people, etc.? How often do you use that specified mode of transportation.

Select only ones that apply to you.

Less than 1 1-2 days of 3-4 days of 5-6 days of 7 days of the day a week the week the week the week week Never

TriMet (bus, MAX)

Portland Streetcar

BIKETOWN

Drive alone

Ride own bike

Walk

Carpool (with at

least 2 people in

car)

Take taxi

Ride Lyft or Uber

Use car share

(car2go/ SHARE

NOW)

Ride e-scooter

Other? (please specify)

5. What are the top three places that you go and how do you get there?

Example: I go to the grocery store by bus.

1.

2.

3. 
6. What keeps you from using these transportation modes?

Nothing keeps me
from using
Too expensive
Takes to much
time
Option not
available in my
neighborhood
I don't know how
to use it
I don't know how
to buy tickets
I don't know how
to use the app
I don't have a bank
account or credit
card
I don't want to link
my bank account
or credit card to
the app
Personal safety
concerns
Physical Abilities
Family Size
Not a practical
option for me
I don't have a
drivers license
(car2go)

Are there other things that make it difficult or challenging for you to use these transportation options? 
7. How do you typically get information (i.e. bus, MAX, Streetcar, etc.)?

Transit Screens at your Transit Stop

Transit Screen in your complex lobby

Tri Met app

Internet or other phone apps

I do not look up transit information before trips

Other (please specify)

8. Do you drive professionally for Lyft or Uber?

Yes, I drive for Uber

Yes, I drive for Lyft

Yes, I drive for both Lyft and Uber

No, I do not drive for Lyft or Uber

$\square$ I prefer not to answer

9. The way the Transportation Wallet (pre-paid credit card) is designed, you can use it yourself or share with your family.

Do you intend to use the Transportation Wallet (pre-paid credit card) for yourself or share it with your family?

Use it for myself

Share with my family

I don't know yet

10. Is there anything else you would like to share about how you travel in Portland? 


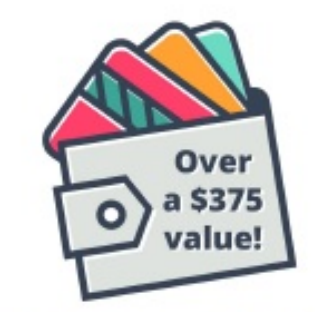

Transportation

Wallet

\section{PBOT}

\section{The following questions are OPTIONAL.}

These questions help PBOT aim for balanced and diverse input from the communities we serve.

11. What is your highest level of education?

High school degree or less

Some college/technical/community college/2-year degree

College degree/ 4-year degree

Post graduate

Prefer not to disclose

12. What is your race or ethnicity? (Please write in) 
13. What is your age?

Under 18

$18-24$

$25-34$

$35-44$

45-54

$55-64$

$65+$

Prefer not to disclose

14. What gender do you identify with?

$\square$ Female

Male

$\square$ Transgender

$\square$ Cisgender

$\square$ Gender Non-conforming

$\square$ Genderqueer

Prefer not to disclose 
15. What language(s) are spoken in your home? (Please select all that apply)

Arabic

Amharic

$\square$ Chinese

$\square$ English

$\square$ French

$\square$ Karen

$\square$ Russian

$\square$ Spanish

$\square$ Somali - Mai Mai

$\square$ Tigrnya

$\square$ Vietnamese

$\square$ Prefer not to disclose

$\square$ Other (please specify)

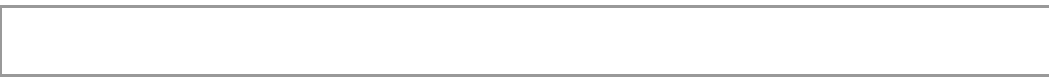

Your feedback will help inform PBOT projects to improve accessible and affordable mobility options for all users. Thank You! 


\section{Transportation Wallet - Participant Survey}

code:

This survey is about the Transportation Wallet, a Portland Bureau of Transportation (PBOT) program. The program included:

- A Transportation Fair, where you could sign up for transportation services and meet representatives of TriMet, BIKETOWN, Lyft, escooter companies like Lime, Shared, Razor, Spin, and Bolt.

- A U.S. Bank pre-paid Visa card with $\$ 308$ to be used on transportation. In this survey, we also call this card the Transportation Wallet.

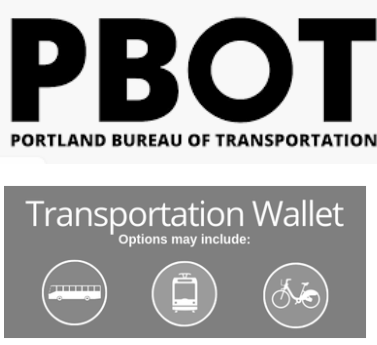

Portland State University is doing this survey. We want to understand how you used the Transportation Wallet, what services you used, what you liked, and what you didn't like.

\section{Portland State}

You are not required to participate. You may skip any questions you choose. We will not report any identifying information.

1. Did you attend a Transportation Wallet Transportation Fair? ${ }_{1} \square$ Yes ${ }_{\theta} \square$ No (skip to Question 3)

2. About your experience at the Transportation Fair

How useful was ...

$\begin{array}{ccc}\text { Not } & \text { Somewhat } & \text { Very } \\ \text { Useful } & \text { Useful } & \text { Useful }\end{array}$

a. ... Talking to transportation companies (e.g. TriMet, BIKETOWN, scooter providers, etc.)

b. ... Seeing the equipment (e.g. bikes, scooters, etc.)

c. ... Signing up for reduced fare program (TriMet)

d. ... Signing up for other services at the fair.

e. ... Getting information about the pre-paid US Bank card

f. ... Having the fair located near to my home (or in my building)

g. ... Attending the Transportation Fair - overall

3. Was it easy or hard to ...

Easy Moderate Hard
a. ... Understand the purpose of the Transportation Wallet
b. ... Sign up for transportation services
c. ... Use the $\$ 308$ U.S. Bank pre-paid Visa card 
4. Do you agree or disagree with each of these statements?

NOTE: Please consider the period prior to recent COVID-19 related closures

\begin{tabular}{|c|c|c|c|}
\hline Because of the Transportation Wallet ... & Disagree & Agree & $\begin{array}{l}\text { I don't } \\
\text { know }\end{array}$ \\
\hline a. ... I am taking more trips overall & ${ }_{1} \square$ & ${ }_{2} \square$ & ${ }_{3} \square$ \\
\hline b. ... I saved money on my normal transportation costs & ${ }_{1} \square$ & ${ }_{2} \square$ & ${ }_{3} \square$ \\
\hline $\begin{array}{l}\text { c. ... I went to work related activities (e.g. job interviews or } \\
\text { trainings) that I could not have gone to otherwise }\end{array}$ & $\square$ & ${ }_{2} \square$ & ${ }_{3} \square$ \\
\hline $\begin{array}{l}\text { d. ... I went to important appointments (e.g. doctor appointments) } \\
\text { for myself or my family that I could not have gone to otherwise }\end{array}$ & $\square$ & ${ }_{2} \square$ & ${ }_{3} \square$ \\
\hline $\begin{array}{l}\text { e. ... I went to school-related activities that I could not have gone } \\
\text { to otherwise }\end{array}$ & ${ }_{1} \square$ & ${ }_{2} \square$ & ${ }_{3} \square$ \\
\hline $\begin{array}{l}\text { f. ... I was able to get to places that I didn't have any way to get to } \\
\text { before }\end{array}$ & ${ }_{1} \square$ & ${ }_{2} \square$ & ${ }_{3} \square$ \\
\hline $\begin{array}{l}\text { g. ....I tried using new modes (like E-scooters or BIKETOWN) I } \\
\text { had never used before }\end{array}$ & ${ }_{1} \square$ & ${ }_{2} \square$ & ${ }_{3} \square$ \\
\hline h. ... managing my monthly budget was less stressful & ${ }_{1} \square$ & ${ }_{2} \square$ & ${ }_{3} \square$ \\
\hline $\begin{array}{l}\text { i. ... my household had more flexibility in how we get around } \\
\text { (e.g. car available for use by others) }\end{array}$ & ${ }_{1}[$ & ${ }_{2} \square$ & $\square$ \\
\hline
\end{tabular}

5. If I didn't have the Transportation Wallet, I would have made more trips by ...

(Select all that apply)
TriMet
Bike
$\square$ Walk
Car
$\square$ Uber / Lyft
None of these
Taxi
$\square$ Other

6. What was the best thing about the Transportation Wallet?

\section{What would you change about the Transportation Wallet?}

8. Did you use the $\$ 308$ yourself or shared with other people in your household?
Mainly for myself

Shared with other members of my household Other 


\section{Questions about using TriMet}

a. Did you sign up for the reduced fare pass at the Transportation Fair?

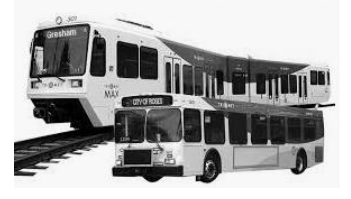

$\square$ Yes $\quad 2 \square$ No, I signed up some other time $\quad{ }_{3} \square$ No, I am not signed up

b. How many trips did you take on Trimet using the Transportation Wallet (annual pass / HOP card)?

${ }_{1} \square 0 /$ None $\quad{ }_{2} \square 1$ to $5 \quad{ }_{3} \square 6$ to $14 \quad{ }_{4} \square 15$ to $24 \quad{ }_{5} \square 25$ or more

if 0, (no trips on TriMet) skip

to Question 9 f below)

c. Using the Transportation Wallet, what types of trips did you take using TriMet?

(Select all that apply)

$\square$ To / from work or school

Shopping / Errands

$\square$ Other related work trips

Social / Recreation / Dining

$\square$ Other

d. Think about the trips you took on TriMet using the Transportation Wallet.

\begin{tabular}{|c|c|c|c|}
\hline $\begin{array}{l}\text { Are each of the statements below true for your TriMet } \\
\text { trips? }\end{array}$ & $\begin{array}{l}\text { Always } \\
\text { False }\end{array}$ & $\begin{array}{l}\text { Sometimes } \\
\text { True }\end{array}$ & $\begin{array}{l}\text { Always } \\
\text { True }\end{array}$ \\
\hline $\begin{array}{l}\text { i. Using TriMet saved me time compared to my other } \\
\text { options }\end{array}$ & ${ }_{1} \square$ & ${ }_{2} \square$ & ${ }_{3} \square$ \\
\hline $\begin{array}{l}\text { ii. Using TriMet, I was able to get places I otherwise } \\
\text { could not }\end{array}$ & ${ }_{1} \square$ & ${ }_{2} \square$ & ${ }_{3} \square$ \\
\hline iii. I enjoyed taking TriMet & ${ }_{1} \square$ & ${ }_{2} \square$ & ${ }_{3} \square$ \\
\hline $\begin{array}{l}\text { iv. I only took TriMet because I had the Transportation } \\
\text { Wallet }\end{array}$ & ${ }_{1} \square$ & ${ }_{2} \square$ & ${ }_{3} \square$ \\
\hline $\begin{array}{l}\text { v. I am taking transit more because of the Transportation } \\
\text { Wallet }\end{array}$ & ${ }_{1} \square$ & ${ }_{2} \square$ & ${ }_{3} \square$ \\
\hline
\end{tabular}

e. After you spend all the money on your Transportation Wallet (or when your TriMet annual pass expires), will you still use TriMet?

${ }_{1} \square$ Yes, about the same amount

${ }_{2} \square$ Yes, but I will take fewer trips

${ }_{3} \square$ No, I will no longer use TriMet

$f$. Is there anything that stops you from using TriMet (or using it more)? 


\section{Questions about using Uber or Lyft}

a. Did you sign up for either Uber or Lyft at the Transportation Fair?

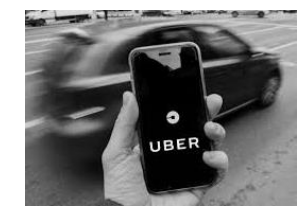

${ }_{1} \square$ Yes $\quad{ }_{2} \square$ No, but I signed up some other time ${ }_{3} \square$ No, I am not signed up for either

b. How many trips did you take with Uber or Lyft using the Transportation Wallet?
${ }_{1} \square 0$ / None
$\square 1$ to 5
$\square 6$ to 14
${ }_{4} \square 15$ to 24
${ }_{5} \square 25$ or more

if 0, (no trips on Uber or Lyft)

skip to Question $10 \mathrm{f}$ below

c. Using the Transportation Wallet, what types of trips did you take with Uber or Lyft? (Select all that apply)

$\square$ To / from work or school

Shopping / Errands

$\square$ Other related work trips

Social / Recreation / Dining

$\square$ Other

d. Think about the trips you took with Uber or Lyft using the Transportation Wallet.

\begin{tabular}{|c|c|c|c|}
\hline $\begin{array}{l}\text { Are each of the statements below true for your Uber / Lyft } \\
\text { trips? }\end{array}$ & $\begin{array}{l}\text { Always } \\
\text { False }\end{array}$ & $\begin{array}{l}\text { Sometimes } \\
\text { True }\end{array}$ & $\begin{array}{l}\text { Always } \\
\text { True }\end{array}$ \\
\hline $\begin{array}{l}\text { i. Using Uber or Lyft saved me time compared to my other } \\
\text { options }\end{array}$ & ${ }_{1} \square$ & ${ }_{2} \square$ & ${ }_{3} \square$ \\
\hline $\begin{array}{l}\text { ii. Using Uber or Lyft, I was able to get places I otherwise } \\
\text { could not }\end{array}$ & ${ }_{1} \square$ & ${ }_{2} \square$ & ${ }_{3} \square$ \\
\hline iii. I enjoyed taking Uber or Lyft & ${ }_{1} \square$ & ${ }_{2} \square$ & ${ }_{3} \square$ \\
\hline $\begin{array}{l}\text { iv. I only took Uber or Lyft because I had the Transportation } \\
\text { Wallet }\end{array}$ & ${ }_{1} \square$ & ${ }_{2} \square$ & ${ }_{3} \square$ \\
\hline $\begin{array}{l}\text { v. I am taking Uber or Lyft more because of the } \\
\text { Transportation Wallet }\end{array}$ & ${ }_{1} \square$ & ${ }_{2} \square$ & ${ }_{3} \square$ \\
\hline
\end{tabular}

e. After you spend all the money on your Transportation Wallet, will you still use Uber or Lyft?

Yes, about the same amount

Yes, but I will take fewer trips

${ }_{3} \square$ No, I will no longer use Uber or Lyft

$f$. Is there anything that stops you from using Uber or Lyft (or using it more)? 
a. How many trips did you take with Taxi services using the Transportation Wallet?
$\square 0 /$ None
$\square 1$ to 5
6 to 14
15 to 24
25 or more

\section{if 0, (no Taxi trips) skip}

to Question 11e below

b. Using the Transportation Wallet, what types of trips did you take using Taxis?

(Select all that apply)

$\square$ To / from work or school

Shopping / Errands

$\square$ Other related work trips

$\square$ Social / Recreation / Dining

$\square$ Other

c. Think about the trips you took with Taxis using the Transportation Wallet.

Are each of the statements below true for your Taxi trips? $\begin{gathered}\text { Always } \\ \text { False }\end{gathered}$ Truetimes Always

i. Using Taxi services saved me time compared to my other options

ii. Using Taxi services, I was able to get places I otherwise could not

iii. I enjoyed taking Taxis

iv. I only took trips by Taxi because I had the Transportation Wallet

v. I am taking Taxis more because of the Transportation Wallet

False True True 


\section{Questions about using BIKETOWN bike share}

a. Did you sign up for BIKETOWN at the Transportation Fair?

$\square$ Yes $\quad{ }_{2} \square$ No, I signed up some other time $\quad{ }_{3} \square$ No, I am not signed up

b. How many trips did you take with BIKETOWN using the Transportation Wallet?
${ }_{1} \square 0$ / None
$\square 1$ to 5
6 to 14
${ }_{4} \square 15$ to 24
${ }_{5} \square 25$ or more

if 0, (no trips on BIKETOWN)

skip to Question $12 f$ below

c. Using the Transportation Wallet, what types of trips did you take using BIKETOWN? (Select all that apply)

$\square$ To / from work or school

$\square$ Shopping / Errands

$\square$ Other related work trips

Social / Dining / Recreation

$\square$ Fun / No particular destination

Other

$\square$ Exercise

d. Think about the trips you took with BIKETOWN using the Transportation Wallet.

\begin{tabular}{|c|c|c|c|}
\hline $\begin{array}{l}\text { Are each of the statements below true for your BIKETOWN } \\
\text { trips? }\end{array}$ & $\begin{array}{l}\text { Always } \\
\text { False }\end{array}$ & $\begin{array}{c}\text { Sometimes } \\
\text { True }\end{array}$ & $\begin{array}{l}\text { Always } \\
\text { True }\end{array}$ \\
\hline $\begin{array}{l}\text { i. Using BIKETOWN saved me time compared to my other } \\
\text { options }\end{array}$ & ${ }_{1} \square$ & ${ }_{2} \square$ & ${ }_{3} \square$ \\
\hline $\begin{array}{l}\text { ii. Using BIKETOWN, I was able to get places I otherwise could } \\
\text { not }\end{array}$ & ${ }_{1} \square$ & ${ }_{2} \square$ & ${ }_{3} \square$ \\
\hline iii. I enjoyed using BIKETOWN & ${ }_{1} \square$ & ${ }_{2} \square$ & ${ }_{3} \square$ \\
\hline $\begin{array}{l}\text { iv. I only took BIKETOWN because I had the Transportation } \\
\text { Wallet }\end{array}$ & ${ }_{1} \square$ & ${ }_{2} \square$ & ${ }_{3} \square$ \\
\hline $\begin{array}{l}\text { v. I am taking BIKETOWN more because of the Transportation } \\
\text { Wallet }\end{array}$ & ${ }_{1} \square$ & ${ }_{2} \square$ & ${ }_{3} \square$ \\
\hline
\end{tabular}

e. After your free membership on BIKETOWN expires, will you still ride BIKETOWN?

${ }_{1} \square$ Yes, about the same amount

${ }_{2} \square$ Yes, but I will take fewer trips

${ }_{3} \square$ No, I will no longer use BIKETOWN

f. Is there anything that stops you from using BIKETOWN (or using it more)? 


\section{Questions about using E-Scooters}

\section{a. Did you sign up for an E-Scooter service at the Transportation Fair?}

${ }_{1} \square$ Yes $\quad{ }_{2} \square$ No, I signed up some other time $\quad{ }_{3} \square$ No, I am not signed up

b. How many trips did you take with E-Scooters using the Transportation Wallet?
${ }_{1} \square 0$ / None
$\square 1$ to 5
$\square 6$ to 14
${ }_{4} \square 15$ to 24
${ }_{5} \square 25$ or more

\section{if 0, (no E-Scooter trips) skip to Question $13 f$ below}

c. Using the Transportation Wallet, what types of trips did you take using E-Scooters? (Select all that apply)

$\square$ To / from work or school

$\square$ Shopping / Errands

$\square$ Other related work trips

$\square$ Social / Dining / Recreation

Fun / No particular destination

$\square$ Other

d. Think about the trips you took with E-Scooters using the Transportation Wallet.

Are each of the statements below true for your E-Scooter trips? Always Sometimes Always

i. Using E-Scooters saved me time compared to my other options

ii. Using E-Scooters, I was able to get places I otherwise could not

iii. I enjoyed using E-Scooters

iv. I only took E-Scooter trips because I had the Transportation Wallet

v. I am taking E-Scooters more because of the Transportation Wallet

e. After you spend all the money on your Transportation Wallet, will you still use eScooters?

${ }_{1} \square$ Yes, about the same amount

$\square$ Yes, but I will take fewer trips

${ }_{3} \square$ No, I will no longer use E-scooters

f. Is there anything that stops you from using E-Scooters (or using them more)? 
14. Did you use any of your Transportation Wallet for anything other than TriMet, Uber or Lyft, Taxis, Biketown, or E-Scooters (for example car share or other services?

${ }_{1} \square$ Yes ${ }_{0} \square$ No

If yes, please briefly describe:

15. Some buildings recently had a new TV / display installed that shows nearby transit (e.g. TriMet bus or MAX) arrival time information (see example ->)

a. Have you noticed a screen like this at your residence? ${ }_{1} \square$ Yes ${ }_{\ominus} \square$ No (skip to question 16).

b. Do you ever use the screen to plan your trips?

${ }_{1} \square$ Yes ${ }_{\theta} \square$ No

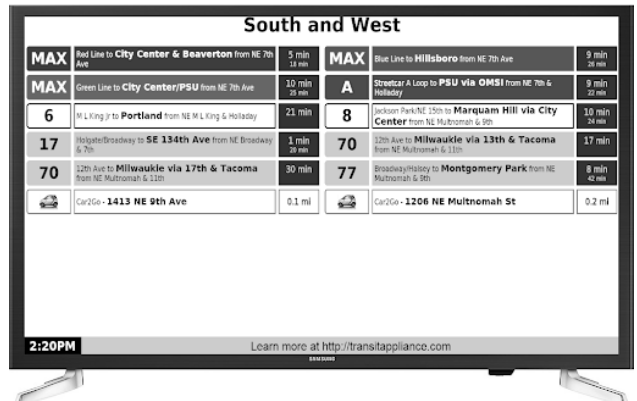

c. Does the screen help you save time or use your time more efficiently compared to when there was no screen?

${ }_{1} \square$ Yes $\quad{ }_{2} \square$ Sometimes ${ }_{\diamond} \square$ No

\section{About Your Transportation Overall}

16. How do you usually get around in the Portland area?

NOTE: Please consider the period prior to recent COVID-19 related closures

\begin{tabular}{|c|c|c|}
\hline Never & $\begin{array}{l}\text { Less than } 1 \\
\text { day a week }\end{array}$ & $\begin{array}{l}\text { 1-4 days } \\
\text { per week }\end{array}$ \\
\hline
\end{tabular}

a. Walk

b. TriMet bus, MAX, or Streetcar

c. Car, truck or van (drive or carpool)

d. Take taxi

e. Uber or Lyft

f. Ride own bike

g. BIKETOWN bike share

h. Car share (e.g. Zipcar, Getaround)

i. Ride e-scooter

j. Other

P a g e | 8 
17. Are these statements about your transportation in Portland true, sometimes true or false? NOTE: Please consider the period prior to recent COVID-19 related closures

Statements about your transportation in Portland

Always Sometimes Always

False True True

a. I avoid taking trips so that I spend less on transportation

b. I need a car to take care of my personal and household travel needs

c. I can take care of most of my travel needs by using public transportation (e.g. TriMet bus / MAX)

d. Other transportation services (such as carshare, bike share, scooter share) are useful to me

e. Sometimes I cannot get to places or activities I want to go to because I don't have any way to get there

f. I don't use transportation services if I have to share personal information (e.g. credit card, travel information)

g. Safety concerns are important considerations for how I choose to get around Portland

h. My travel options are limited because I don't have enough time

i. My travel options are limited due to my physical limitations

About you and your household

(Reminder: You may skip any questions you choose.)

18. Do you ...

\begin{tabular}{|lll|}
\hline Have a driver's license? & ${ }_{1} \square$ Yes & ${ }_{0} \square$ No \\
Own or lease a car? & ${ }_{1} \square$ Yes & ${ }_{0} \square$ No \\
Have access to a car through family or friend & ${ }_{1} \square$ Yes & ${ }_{\ominus} \square$ No \\
Have a transit pass paid by employer & ${ }_{1} \square$ Yes & ${ }_{\ominus} \square$ No \\
Own a bicycle & ${ }_{1} \square$ Yes & ${ }_{\ominus} \square$ No \\
\hline
\end{tabular}

19. What is your work (or school) zip code or address (or nearby cross-street)?

$\square$ Not applicable - I do not work or go to

school outside my home

Zip code ___ _ _ _ OR
Address

20. What is your annual household income?

${ }_{1} \square$ Less than $\$ 15,000$

${ }_{4} \square \$ 35,000-\$ 49,999$

$\$ 15,000-\$ 24,999$

${ }_{5} \square \$ 50,000-\$ 74,999$

$\$ 25,000-\$ 34,999$

$\$ 75,000$ or more

Prefer not to disclose

P a g e $\mid \mathbf{9}$ 
22. Do you have ...

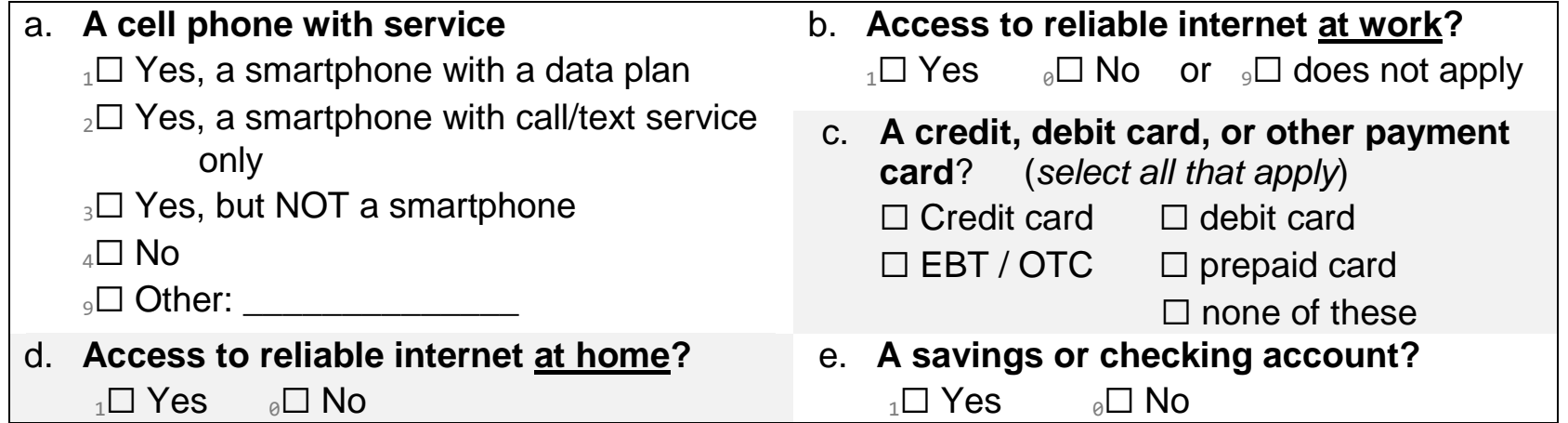

23. Do you have a physical or anxiety condition that seriously limits or prevents you from doing any of the following?
a. Driving a vehicle
${ }_{1} \square$ Yes $\quad{ }_{0} \square$ No
b. Walking outside the home
$\square$ Yes $\quad{ }_{\theta} \square$ No
c. Riding a bicycle
$\square$ Yes $\quad \therefore$ No
d. Using public transit
$\square$ Yes $\quad{ }_{0} \square$ No
e. Taking a taxi or Uber/Lyft
$\square$ Yes $\quad \square$ No
24. What is your highest level of education?
${ }_{1} \square$ High school degree or less
College degree/ 4-year degree
${ }_{2} \square$ Some college / technical /
Post graduate
community college / 2-year degree
Prefer not to disclose

25. Do you consider yourself:

Select all that apply

\begin{tabular}{ll}
\hline$\square$ Hispanic or Latino/a & $\square$ Native Hawaiian / Pacific Islander \\
$\square$ Black of African American & $\square$ Some other race \\
$\square$ White / Caucasian & $\square$ Biracial / Multiracial \\
$\square$ American Indian or Alaska Native & $\square$ Prefer not to disclose \\
$\square$ Asian &
\end{tabular}

26. What is your age?

\begin{tabular}{|llll}
\hline${ }_{1} \square$ 18-24 & ${ }_{3} \square 35-44$ & ${ }_{5} \square 55-64$ & ${ }_{9} \square$ Prefer not to \\
${ }_{2} \square 25-34$ & ${ }_{4} \square$ (55-54 & ${ }_{6} \square 65+$ & disclose \\
\hline
\end{tabular}

27. What gender do you identify with?

$\begin{array}{lll}{ }_{1} \square \text { Female } & { }_{3} \square \text { Non-binary } & 9 \\ { }_{2} \square \text { Male } & { }_{4} \square\end{array}$

28. What language(s) are spoken in your home? Select all that apply

\begin{tabular}{|lll}
\hline English & $\square$ Vietnamese & $\square$ Other \\
$\square$ Spanish & $\square$ Russian & $\square$ Prefer not to disclose \\
$\square$ Chinese & & \\
\hline
\end{tabular}

Is there anything else that you would like to tell us? 